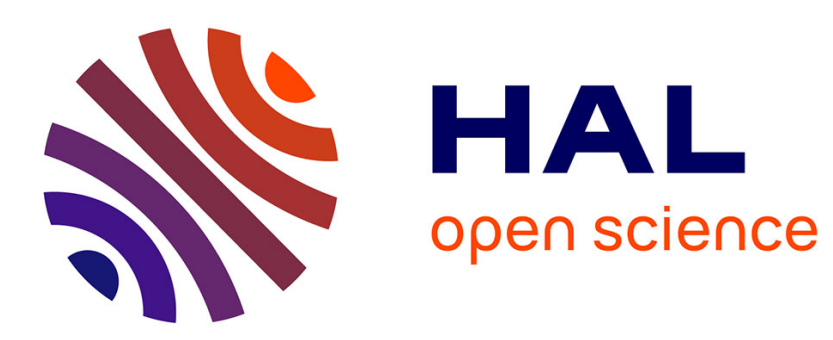

\title{
Kinematic manifestations of localisation phenomena in steels by digital image correlation
}

\author{
Bertrand Wattrisse, André Chrysochoos, Jean-Michel Muracciole, M. \\ Némoz-Gaillard
}

\section{- To cite this version:}

Bertrand Wattrisse, André Chrysochoos, Jean-Michel Muracciole, M. Némoz-Gaillard. Kinematic manifestations of localisation phenomena in steels by digital image correlation. European Journal of Mechanics - A/Solids, 2001, 20 (2), pp.189-211. 10.1016/S0997-7538(00)01113-X . hal-03350172

\section{HAL Id: hal-03350172 \\ https://hal.science/hal-03350172}

Submitted on 21 Sep 2021

HAL is a multi-disciplinary open access archive for the deposit and dissemination of scientific research documents, whether they are published or not. The documents may come from teaching and research institutions in France or abroad, or from public or private research centers.
L'archive ouverte pluridisciplinaire HAL, est destinée au dépôt et à la diffusion de documents scientifiques de niveau recherche, publiés ou non, émanant des établissements d'enseignement et de recherche français ou étrangers, des laboratoires publics ou privés. 


\title{
Kinematic manifestations of localisation phenomena in steels by digital image correlation
}

\author{
B. Wattrisse ${ }^{\mathrm{a}, 1}$, A. Chrysochoos ${ }^{\mathrm{a}, 2}$, J.-M. Muracciole ${ }^{\mathrm{a}, 3}$, M. Némoz-Gaillard $^{\mathrm{b}, 4}$ \\ a Laboratoire de mécanique et génie civil, UMR 5508 CNRS université Montpellier II, CC 081, place E. Bataillon, \\ 34095 Montpellier cedex 05, France \\ ${ }^{\mathrm{b}}$ Laboratoire de mécanique et métrologie, EMA, avenue de Clavières, 30319 Alès cedex, France
}

(Received 1 November 1999; revised 16 June 2000)

\begin{abstract}
The aim of this paper is to show that recent advances made in the field of speckle image processing give valuable information useful in understanding and modelling of localisation phenomena. The potentialities of the proposed imaging method are illustrated by examples extracted from tensile tests performed on steel specimens. Having introduced the underlying motivations of this experimental work, this paper briefly focuses on the image processing technique and its reliability. Then, it describes the characteristics of the strain field within and outside of a propagating Lüders band. The properties of strain states associated with diffuse and localised necking are also investigated. The catalyst role of possible geometrical defects is pointed out. Finally, a method is proposed to construct, despite localisation, a local stress-strain correspondence.
\end{abstract}

digital image correlation / strain measurement / strain localisation / constitutive equations

\section{Introduction}

A stamping process is often difficult to perform in an optimal way because deformations, instead of being regularly distributed in the material, can be concentrated more or less suddenly in certain zones and lead to defects that weaken the part to be formed. In practice, this strain localisation is quite a common phenomenon: it can occur in a wide range of materials (metals, polymers, woods, rocks, etc.), and in very different ways (necking, shear bands, Lüders bands, phase transformation bands, crack tips, etc.).

There have been numerous works on the experimental, theoretical and numerical aspects of such deformation mechanisms. Among the very first studies, the work of Considère in the late 19th century is to be mentioned (Considère, 1885). In uniaxial tension, the Considère criterion associates the inception of necking with the maximum of the applied load. Other theories invoke geometric or material defects to explain the inception of localisation. For Marciniak and Kuczynski, this defect is a band of a lesser thickness within the plate (Marciniak and Kuczynski, 1967). Some theories, which are very popular at the moment, focus on the behaviour of the material. Two main theoretical approaches can be considered.

On one hand, for time-independent behaviour, localisation onset is related to the existence of a bifurcated solution of the rate boundary problem (Hill, 1958). Bifurcation, appearing under the so-called localised mode, can then be physically translated by a spatial discontinuity in the strain-rate field (Rice, 1976). Unfortunately,

\footnotetext{
${ }^{1}$ E-mail: wattrisse@1mgc.univ-montp2.fr

${ }^{2}$ E-mail: chryso@1mgc.univ-montp2.fr

${ }^{3}$ E-mail: muraccio@1mgc.univ-montp2.fr

${ }^{4}$ E-mail: nemoz@ema.fr
} 
as soon as the uniqueness of the solution is lost, the problem becomes mathematically ill-posed. This difficulty may be overcome by introducing a characteristic length scale, either directly in the constitutive equations of the model (non-local approach) (Pijodier-Cabot and Benallal, 1993), or by having recourse to models taking gradients of a second order into account (Aifantis, 1992).

On the other hand, for time-dependent behaviour, linear or non linear perturbation analyses are frequently used. At any moment, the stability of the solution of the thermomechanical problem is checked by superimposing a perturbation. This perturbation can be formally interpreted as a virtual defect. When it tends to increase, the perturbed solution becomes unstable and localisation occurs (Bai, 1982; Fressengeas and Molinari, 1985).

To finish this non-exhaustive presentation, Lüders or Portevin-le Chatelier bands have also been studied at a microstructural scale (Estrin and Kubin, 1988; Zaiser and Hähner, 1997).

In this paper, we aim to show that recent advances made in mechanical imaging offer new and very interesting experimental analysis tools for investigating localisation phenomena. These tools, giving access to whole-field measurements, are particularly fitted to studying strain patterns. Therefore, we present an image processing, based on digital image correlation, that has been developed and used to observe the kinematic effects associated with two particular manifestations of strain localisation: Lüders band propagation and necking.

These two different localisation modes can be encountered in several materials. For example, Lüders bands occur in low-carbon steel, stainless steel or aluminium alloys (Strudel, 1979). Necking takes place in some amorphous and semi-crystalline polymers and quite generally in metallic materials. The industrial implications of these two phenomena are of paramount importance: Lüders band generate vermiculations and necking induces thickness variations which may weaken the structure and lead to fracture.

In section 2, we briefly introduce the experimental set-up designed to measure, throughout the test, strain and strain-rate fields. Aware of the fundamental influence of experimental results on theoretical views, a detailed check of the performances of the data processing was fully presented in a separate paper (Wattrisse et al., 2000). We then focus on the two localisation mechanisms mentioned above. In section 3 , we discuss the characteristics of the strain field within the Lüders band during its development and its propagation. In section 4, we underline the early and gradual development of necking. The weakness of dynamic effects in the case of a velocitycontrolled tensile test is also highlighted. In the last section, the quasi-staticity of the localisation phenomena is finally used to construct, despite localisation, a stress tensor.

\section{Experimental set-up}

The experimental set-up involves a $100 \mathrm{kN}$ tension-compression, servo-mechanic testing machine. Digital images are recorded during the test by a C.C.D. camera, set in front of the sample. The lens axis of the camera is held fixed with reference to the frame of the testing machine and remains perpendicular to the surface of the sample (figure 1).

\subsection{Camera installation}

An image processing gives the space-time evolution of various kinematic variables (displacement, velocity, strain, strain-rate, etc.) on the sample surface.

Correlation techniques on digital images have been used for a long time to measure in-plane displacement components on plane samples, (Bailey et al., 1976; Bruck et al., 1989; Choi and Shah, 1997). Concerning 


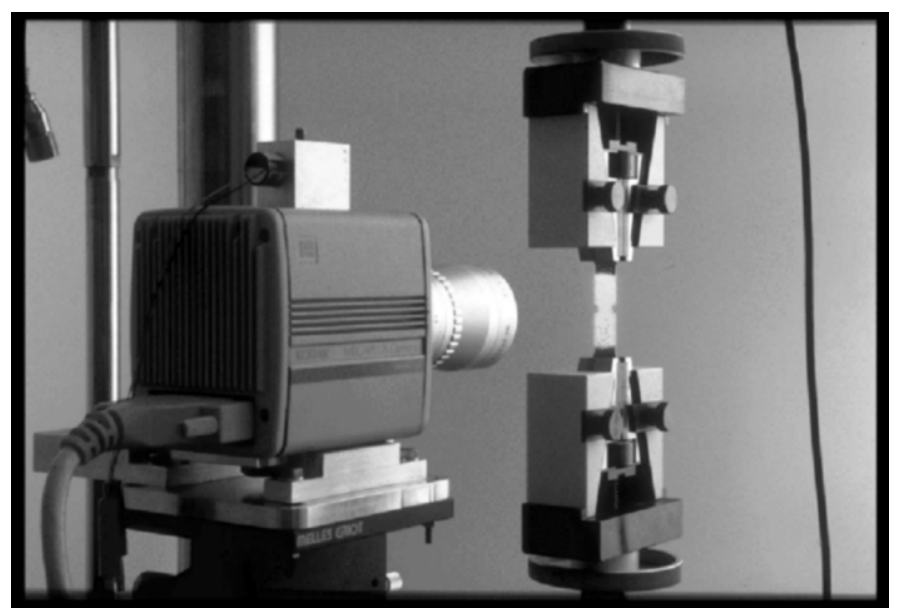

Figure 1. Photograph of the experimental set-up.

the lighting mode, we worked with white light rather than coherent light as it is less sensitive to out-ofplane movements and to the increase of surface roughness due to strain hardening that both disturb the data analysis. Of course, for natural lighting, the sample surface must have sufficient contrast to enable correlation computations. Some materials, naturally contrasted (wood, rocks, etc.), do not need particular preparation, while others (steels), are artificially speckled by using paint.

The camera must be carefully set so that the detector remains parallel to the sample surface. Each out-ofplane movement (translation or rotation) produces a parallax error which distorts the images. In order not to disturb the interpretation of the measurements, it is of great importance to be able to minimise these distortions. Therefore, a first positioning is made by the use of a three-axis rotational stage allowing easy tilt corrections. Fine adjustments are then achieved by vertical translation of the sample in front of the camera. The comparison between strain fields associated with rigid body motions (identically equal to zero) and the strain measurements, enables us to check and optimise the alignment procedure. A typical error on the strain measurements due to the setting up of the camera, is about $1.10^{-4}$ to $2 \cdot 10^{-4}$.

\subsection{Image processing}

The image processing is systematically realised after the test, and can be decomposed into two steps. First, the displacement field is estimated. Generally speaking, the displacement of each point $P\left(x_{\mathrm{P}}, y_{\mathrm{P}}\right)$, located on the surface of the sample, has three components: 2 in-plane components, say $U$ and $V$, and 1 out-ofplane component, say $W$ (see figure 2). If the components $U$ and $V$ can be directly computed by a digital image correlation, $W$ will be estimated by using the couples of data $(U, V)$ and a supplementary mechanical assumption. Second, the strains (or the strain-rates) are then derived from the displacements by space (and time) differentiation. Each computational step uses particular numerical processing (Wattrisse, 1999). A brief outline is given in the following text.

\subsubsection{Principles}

The in-plane components of the displacement vector are given by a direct digital image correlation computation. Between two consecutive images $I_{1}$ and $I_{2}$, the normalised discrete intercorrelation function 


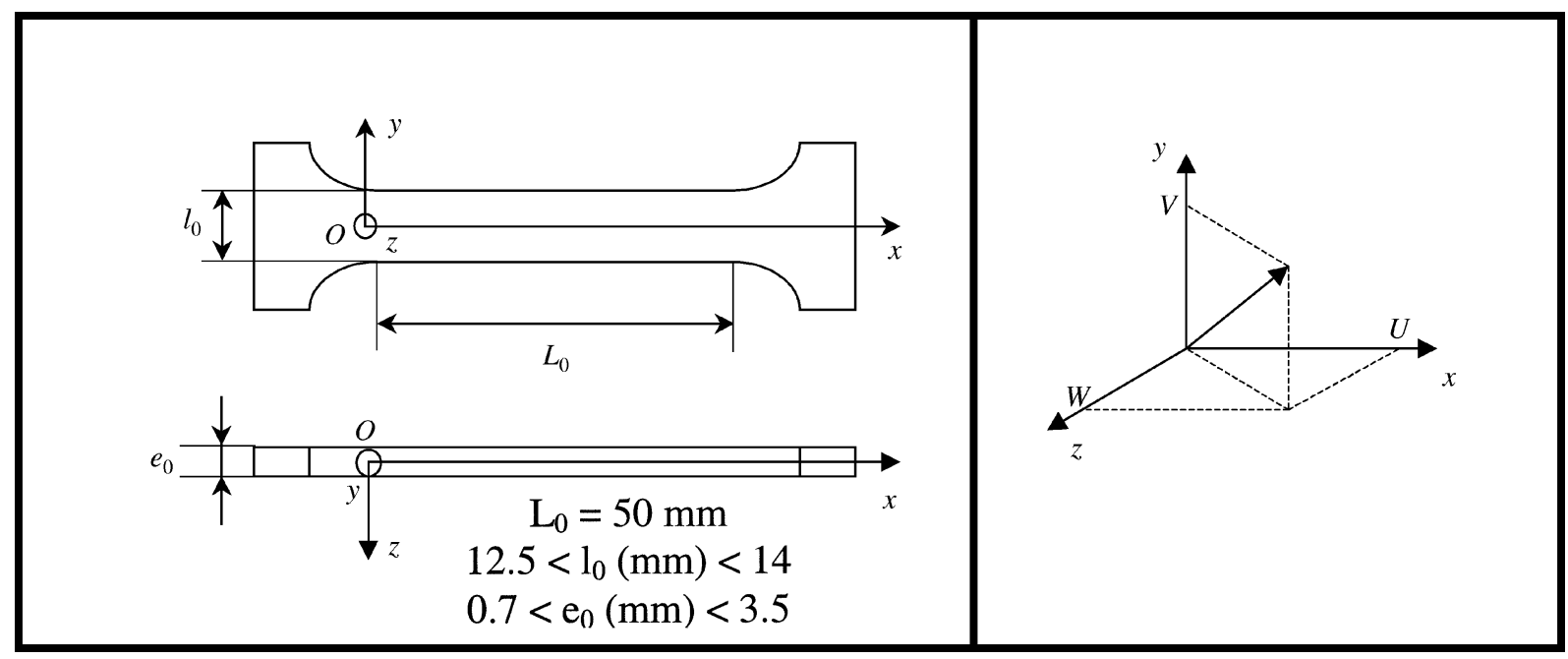

Figure 2. Schematic representation of the sample; $(0, x, y, z)$ is the sample frame of reference; $\left(e_{0}, l_{0}, L_{0}\right)$ defines the initial geometry of the sample gauge part; $(U, V, W)$ are the components of the displacement vector.

$\bar{\varphi}$, computed at point $M$ is defined by:

$$
\underset{(k, l) \in\left[\frac{-R Z}{2}, \frac{R Z}{2}\right]}{\bar{\varphi}(k, l)}=\frac{\sum_{i=-C Z / 2}^{C Z / 2} \sum_{j=-C Z / 2}^{C Z / 2} I_{1}(i, j) \cdot I_{2}(i+k, j+l)}{\sqrt{\sum_{i=-C Z / 2}^{C Z / 2} \sum_{j=-C Z / 2}^{C Z / 2} I_{1}^{2}(i, j)} \cdot \sqrt{\sum_{i=-C Z / 2}^{C Z / 2} \sum_{j=-C Z / 2}^{C Z / 2} I_{2}^{2}(i+k, j+l)}},
$$

where:

- $C Z$ is the number of pixels defining the correlation zone (i.e. $M$ 's neighbourhood corresponding to a local optical signature of point $M$ ),

$-R Z$ is the number of pixels defining the research zone.

The displacement components $U$ and $V$ are given by the maximum of $\bar{\varphi}$. The definition (1) only allows displacement measurements of one-pixel resolution. To reach a subpixel resolution, a local interpolation is performed in the vicinity of the discrete maximum of $\bar{\varphi}$ (Oulamara et al., 1988).

When elastic strain remains small, the metallic alloys are generally considered as incompressible materials. The incompressibility gives a relationship between in-plane and out-of-plane displacement components. In the framework of finite transformation, incompressibility can be written as:

$$
\operatorname{det}(\underline{\underline{F}}(M))=1
$$

where $\underline{\underline{F}}$ is the gradient tensor of the transformation.

If the transformation is assumed to be homogeneous along the sample thickness (thin sheet assumption), equation (2) becomes:

$$
\frac{\partial W}{\partial z}=\left\{\operatorname{det}\left(\begin{array}{cc}
1+\frac{\partial U}{\partial x} & \frac{\partial U}{\partial y} \\
\frac{\partial V}{\partial x} & 1+\frac{\partial V}{\partial y}
\end{array}\right)\right\}^{-1}-1 .
$$

Then, the integration of equation (3) gives the out-of-plane component of the displacement vector $W$. 
To achieve accurate strain measurements, the displacement field is to be filtered before any differentiation. We chose a smoothing technique based on a local least square (linear or quadratic) approximation of the discrete displacement data which also allows the computation of the derivatives.

\subsubsection{Checking the image processing}

The performance of the image processing was tested both for analytic and experimental cases corresponding to rigid body motions (translation or rotation), or to homogeneous or heterogeneous straining.

The influence of all the computation parameters on the displacement and strain measurement was tested. Using standard parameters, the accuracy on the displacement calculation is about $5 \cdot 10^{-2}$ pixel and the accuracy on the strain measurement is $5 \cdot 10^{-4}$.

The validity check of the out-of-plane displacement computation was performed by comparing the thickness evolution of a steel sample after a tensile test given by a three-axis measurement machine, with the one given by the computation.

\subsection{Presentation mode of the experimental results}

Whilst data intensive imaging techniques generally provide a lot of useful information. In our case, they give access to time evolution of scalar fields (kinetic energy), but also fields of vectorial nature (displacement, velocity, acceleration) and even tensor fields (strain, strain-rate). A first possibility to present this information in a concise and simple way, is to plot the temporal evolution of scalar profiles captured along the longitudinal axis of the sample. The scalar entity may be a given component of a tensor or a certain norm (euclidian norm of the velocity, second invariant of the strain tensor, etc.). To further simplify interpretation of the figure, contour plots can be chosen to quickly visualise the evolution of the phenomena. The classical stress-strain diagram is over-plotted to give the reader a familiar landmark which is useful to link the local pattern of the strain measurements to the loading state of the sample. The conventional stress is defined by:

$$
\sigma_{\mathrm{C}}=\frac{F}{S_{0}}
$$

where $F$ is the loading force and $S_{0}$ is the initial cross-section. If $L$ and $L_{0}$ represent the current and initial gauge lengths of the sample respectively, the conventional strain is written as:

$$
\varepsilon_{\mathrm{C}}=\frac{L-L_{0}}{L_{0}}
$$

Two other measurements of strain and strain-rate are used throughout this paper. They are defined in the framework of finite transformation (Germain, 1986; Rougée, 1997). The Lagrangian strain tensor $\underline{\underline{E}}$ is written as:

$$
\underline{\underline{E}}=\frac{1}{2}\left(\underline{\underline{F}}^{\mathrm{T}} \underline{\underline{F}}-\underline{\underline{1}}\right) \text {. }
$$

To quantify volume variations, it is convenient to use the logarithmic Hencky tensor inasmuch as its trace equals zero for any incompressible material. Besides, this strain measurement is very often used in the onedimensional processing of tensile tests. This tensor is classically defined by:

$$
\underline{\underline{\varepsilon}}=\log (\underline{\underline{U}}),
$$


Table I. Standard chemical compositions of steels (\%).

\begin{tabular}{ccccccccccc}
\hline & $\mathrm{C}$ & $\mathrm{Mn}$ & $\mathrm{P}$ & $\mathrm{S}$ & $\mathrm{Si}$ & $\mathrm{Al}$ & $\mathrm{Cu}$ & $\mathrm{N}$ & $\mathrm{Ni}$ & $\mathrm{Ti}$ \\
\hline 3CTi & 0.07 & 0.3 & $<0.017$ & $<0.1$ & $<0.025$ & 0.03 & $<0.04$ & $<0.007$ & 0.015 \\
SOLDUR 355 & 0.5 & 0.35 & $<0.02$ & $<0.01$ & $<0.04$ & 0.03 & $<0.1$ & $<0.009$ & 0.005 & \\
HR55 & 0.135 & 1.12 & $<0.02$ & $<0.002$ & $<0.11$ & 0.04 & $<0.01$ & 0.005 & \\
M323 & 0.025 & 0.2 & 0.008 & & 0.005 & 0.06 & & 0.05 & \\
\hline
\end{tabular}

where $\underline{\underline{U}}$ is the symmetric definite positive tensor coming from the polar decomposition of $\underline{\underline{F}}, \underline{\underline{F}}=\underline{\underline{R}} \cdot \underline{\underline{U}}, \underline{\underline{R}}$ being a rotation. According to the frame of reference defined in figure 1, its representative matrix $\varepsilon$ is noted:

$$
\varepsilon=\left[\begin{array}{ccc}
\varepsilon_{x x} & \varepsilon_{x y} & \varepsilon_{x z} \\
\varepsilon_{x y} & \varepsilon_{y y} & \varepsilon_{y z} \\
\varepsilon_{x z} & \varepsilon_{y z} & \varepsilon_{z z}
\end{array}\right] .
$$

Another way of presenting strain and strain-rate measurements is to show their surface distribution at a given time. In this case, the ordinates are parallel to the longitudinal direction of the sample ( $O x$ axis; see figure 1$)$ while the abscissas are parallel to its width (Oy axis).

\subsection{Loading and materials}

The development of localisation has been studied during tensile tests performed at room temperature and at constant cross-head velocity for four grades of mild steels. The steels, marketed by the French steel company Sollac, will be termed, in what follows, by their commercial references. The metallurgic treatments, their microstructures, and some mechanical properties of these steels can be found in (Béranger et al., 1994). The chemical composition of these four steels are given in table I. Two grades belong to the family of construction steels (HR55 and SOLDUR 355), while the two others are used for cold stamping (M323, 3CTi).

\section{Propagation of Lüders bands: a sudden but temporary phenomenon}

In the vicinity of the yield stress, the sample may deform in one or several narrow zones, known as the Lüders bands, which move along the longitudinal axis of the specimen. This propagation induces the so-called plastic plateau. Such mechanisms are often described at the microscopic level by the dislocation theory (Estrin and Kubin, 1991; Béranger et al., 1994; Hähner, 1994). The atoms of carbon, nitrogen or oxygen, which are relatively small compared to the iron atoms, tend to fix the dislocation by diffusing in the interstitial sites. The stress amplitude required to move those which are anchored is much higher than the one needed for dislocation glide. Their rapid release and subsequent multiplication induce a 'drag and drop' phenomenon, which propagates in a band. Naturally, this preferentially occurs in a stress concentration zone.

At a more macroscopic scale, we analyse the strain data given by the speckle image processing. We describe the strain state within the band and we discuss the influence of a skin-pass operation on the development of such a band. 


\subsection{Inception and propagation}

For the sake of simplicity, the inception mechanisms will be first illustrated in the case of SOLDUR 355 steel which shows the propagation of a single band. Figure 3 gives the stress-strain diagram $\left(\sigma_{\mathrm{C}}, \varepsilon_{\mathrm{C}}\right)$ and contour plots of the strain distributions at the different loading states spotted in the tension curve. The strain maps correspond to the spatial distribution of the component $E_{x x}(x, y, t)$ at these successive loading states.

Figure 3 reveals that two bands appear whereas the structure still seems to be elastically loaded. They arise in the upper and lower left sides of the sample and gradually invade the width of the metal strip. The upper band develops faster whereas the lower one stops propagating. As soon as the upper band reaches the other side of the specimen, it begins a longitudinal propagation along the sample axis. This initiation mode is qualitatively well known by metallurgists and has been already described, for example, in (Béranger et al., 1994). Here, the strain data can be used to estimate the velocity of this lateral progression. As can be seen in figure 3, the development being regular, the velocity is determined by dividing the sample width by the time consumed. This calculation gives a transversal velocity of around $1 \mathrm{~mm} \cdot \mathrm{s}^{-1}$.

Figure 4 represents longitudinal profiles of strain-rate during the band propagation. First, it shows that, at our observation scale, the strain-rate equals approximately zero outside the band. Secondly, at first sight, the band propagates at a constant velocity along the sample axis. It is important to note that the apparent width of the band $w_{\mathrm{LB}}$ must not be interpreted as its real size. In fact, this width corresponds to the space covered by the band between the recording of two successive images and thus depends on the frame rate of the camera. Moreover the measured strain-rate amplitude within the band also corresponds to the one averaged between the recording of two images.

To calculate the band velocity we suppose that its current location corresponds to the locus where strainrate is maximum. Plotting the position of the band according to time gives a straight line of which the slope corresponds to the average velocity. Figure $5 a$ illustrates this construction for a test performed on a SOLDUR 355 sample. It confirms that the position of the band moves linearly according to time and gives a velocity of about $1.4 \mathrm{~mm} \cdot \mathrm{s}^{-1}$.

(a) (b) (c) (d) (e) (f) $\mathrm{E}_{\mathrm{xx}}\left(10^{-2}\right)$
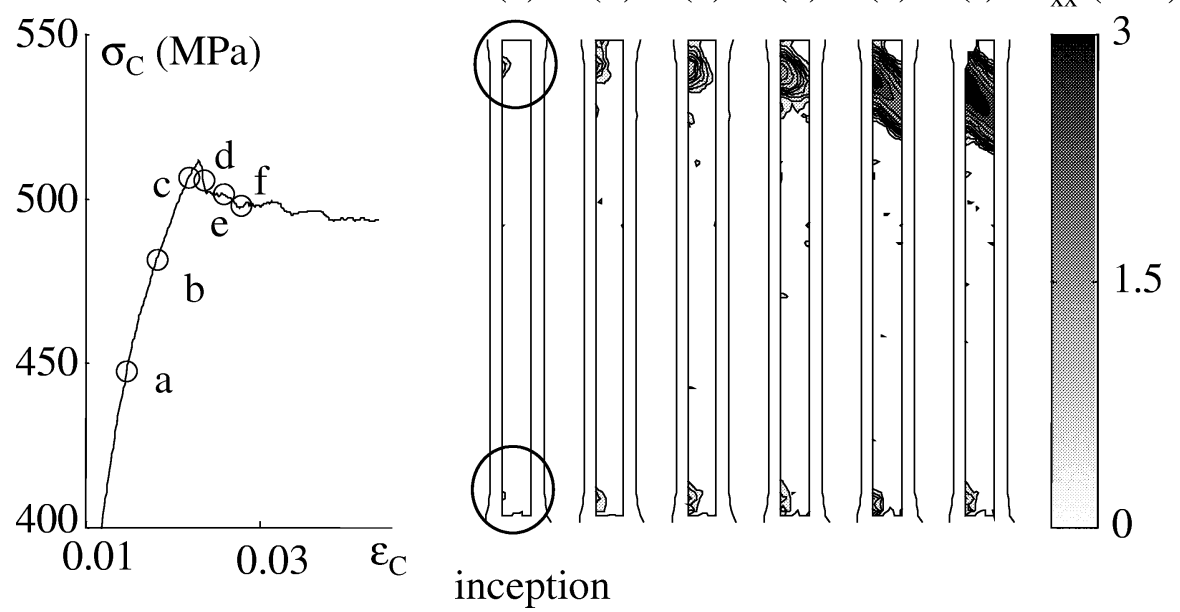

Figure 3. Transversal propagation of Lüders band; distribution of the axial Lagrangian strain $E_{x x}(x, y, t)$ for various loading states, during a monotone tensile test, performed at constant velocity $v_{\mathrm{CH}}=40 \mu \mathrm{m} . \mathrm{s}^{-1}$ on a SOLDUR 355 steel sample. $v_{\mathrm{CH}}$ is the cross-head displacement velocity of the testing machine. 


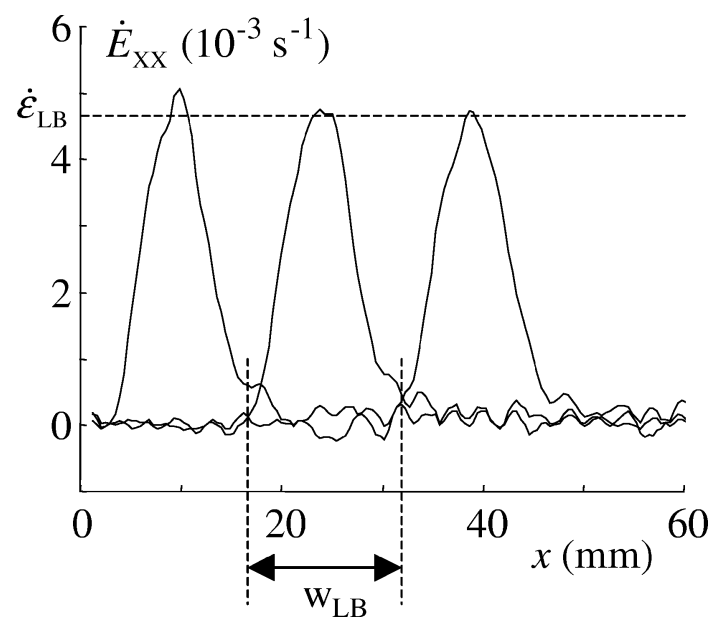

Figure 4. Propagation of Lüders band; longitudinal profiles of axial Lagrangian strain rate $\dot{E}_{x x}(x, y=0)$ at three times; velocity $v_{\mathrm{CH}}=40 \mu \mathrm{m} . \mathrm{s}^{-1}$, SOLDUR 355 steel.

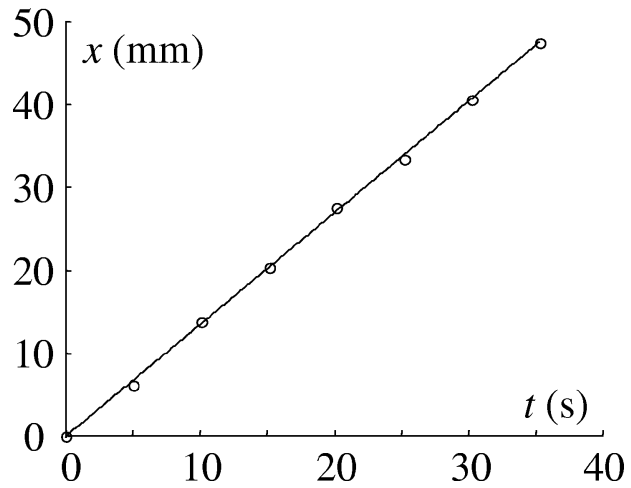

(a)

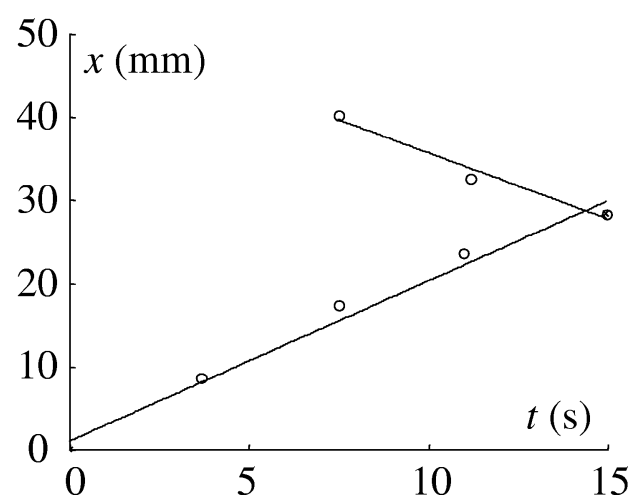

(b)

Figure 5. Experimental determination of the axial velocity of the Lüders band for a monotone tensile test, performed at constant velocity $v_{\mathrm{CH}}=$ $40 \mu \mathrm{m} \cdot \mathrm{s}^{-1}$ : (a) SOLDUR 355; (b) HR55.

In the case of HR55 steel for which two bands propagate, we checked that the velocity of the two bands had comparable magnitudes: $v_{\mathrm{LB}}=1.6 \mathrm{~mm} . \mathrm{s}^{-1}$ for the lower band and $v_{\mathrm{LB}}=1.9 \mathrm{~mm} . \mathrm{s}^{-1}$ for the upper one (see figure $5 b)$.

The longitudinal velocity of the band $v_{\mathrm{LB}}$ is often related to the cross-head velocity $v_{\mathrm{CH}}$ and to the 'Lüders strain' $\varepsilon_{\mathrm{LB}}$, corresponding to the plastic strain reached at the end of the plastic plateau (Hähner, 1994):

$$
v_{\mathrm{CH}}=\varepsilon_{\mathrm{LB}} \nu_{\mathrm{LB}} .
$$

More generally, if $n$ bands coexist and generate the same strain $\varepsilon_{\mathrm{LB}}-$ an assumption reasonably justified by the experimental results shown in section 3.3., their velocities are then the same and the geometrical relation (9) becomes:

$$
v_{\mathrm{CH}}=n \varepsilon_{\mathrm{LB}} \nu_{\mathrm{LB}} \text {. }
$$




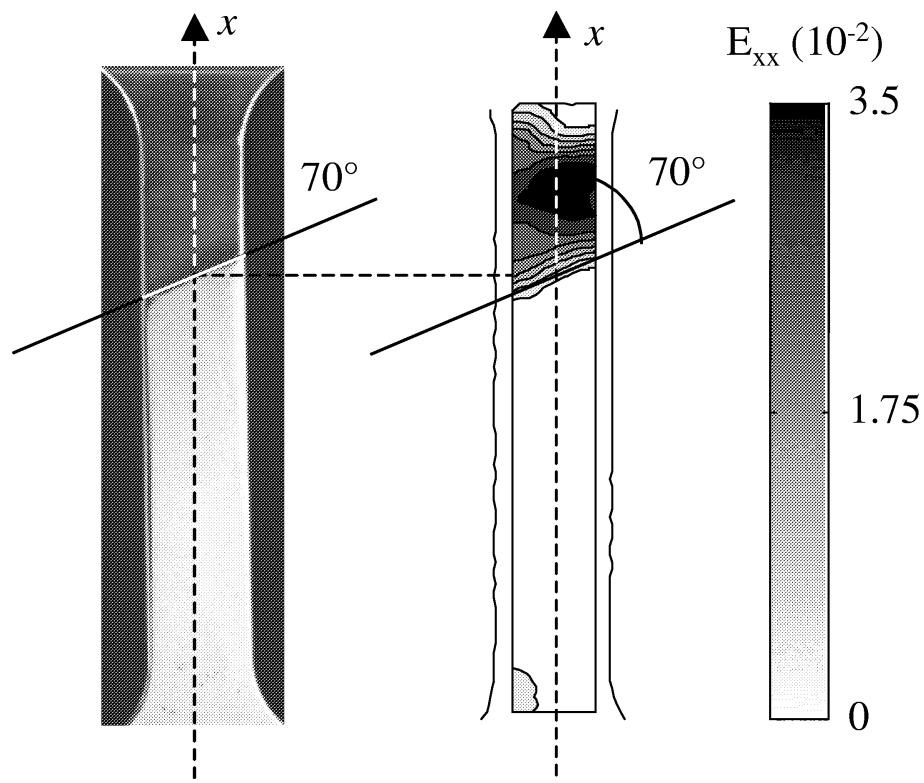

Figure 6. Experimental determination of the angle between the band and the loading axis on a sample of SOLDUR 355 steel: (a) polished sample; (b) strain field on the sample surface.

Table II. Comparison between theoretical and experimental Liiders bands velocities.

\begin{tabular}{ccccc}
\hline Material & $\nu_{\mathrm{CH}}\left(\mathrm{mm} . \mathrm{s}^{-1}\right)$ & $\nu_{\mathrm{LB}}\left(\mathrm{mm} . \mathrm{s}^{-1}\right)$ & $\varepsilon_{\mathrm{LB}}$ & $n \nu_{\mathrm{LB}} \varepsilon_{\mathrm{LB}}\left(\mathrm{mm} . \mathrm{s}^{-1}\right)$ \\
\hline SOLDUR 355 & 0.04 & 1.17 & 0.034 & 0.0398 \\
SOLDUR 355 & 0.04 & 1.37 & 0.03 & 0.0411 \\
SOLDUR 355 & 0.05 & 1.35 & 0.038 & 0.0513 \\
SOLDUR 355 & 0.15 & 5.38 & 0.031 & 0.1668 \\
HR55 & 0.04 & 1.55 & 0.014 & 0.0434 \\
\hline
\end{tabular}

The relations (9) and (10) were checked respectively in the case of SOLDUR 355 and HR55. The velocities of the bands were computed as described above and the strain $\varepsilon_{\mathrm{LB}}$ carried by the bands was given by a local measurement. Table II shows the good agreement between the theoretical predictions of relations (9) and (10) and the experimental measurements.

\subsection{Band orientation}

The relation between the geometrical characteristics of the bands and the microscopic properties of the material (grain size, etc.) are also often mentioned in the literature (Hähner, 1994). The angle between the band and the loading axis is traditionally determined by polishing the sample. The propagation of the band corresponds to the propagation of a 'plastic wave' which affects the surface roughness and modifies the sample polish. This delicate manipulation can be henceforth avoided, the use of strain-rate measurements enabling us to easily determine the bands orientation. Figure 6 illustrates the comparison of the results obtained by these two methods in the case of a single band (SOLDUR 355 steel). The angle between the loading axis and the band is close to $70^{\circ}$. Note that this direction differs from the maximum shear direction $\left(45^{\circ}\right)$. 
(a)

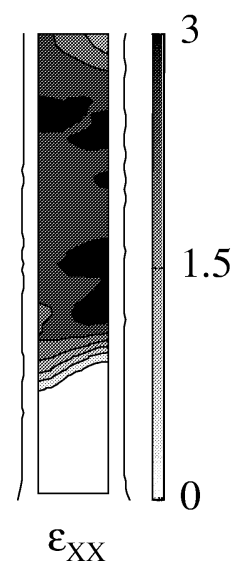

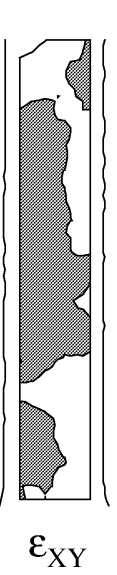

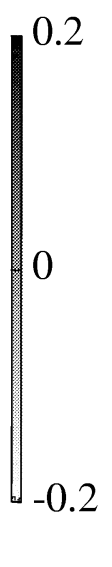

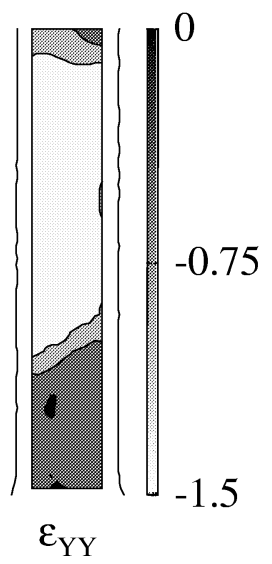

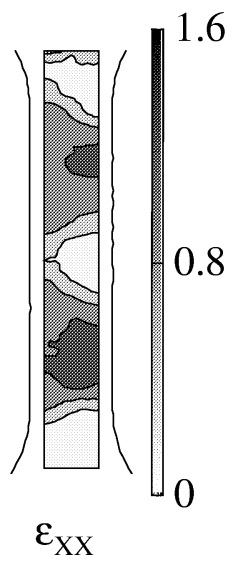

(b)

Figure 7. Components $\varepsilon_{x x}, \varepsilon_{x y}$ and $\varepsilon_{y y}$ of the Hencky strain tensor during the propagation of a band: (a) SOLDUR 355 steel: one band; (b) HR55 steel: two bands. Strain unit: $(\%)$.

\subsection{Strain state within Lüders band}

Figure 7 represents the distribution of the three in-plane components of the Hencky strain tensor for a loading state corresponding approximately to the middle of the plastic plateau. Strain measurements are compatible with a tension strain state: the rotation of the principal axes of the Hencky tensor is small so that the component $\varepsilon_{x y}$ of the strain tensor remains negligible $\left(\left|\varepsilon_{x y}\right| \leqslant 0.2 \%\right)$, and the contraction ratio $\bar{v}=-\varepsilon_{y y} / \varepsilon_{x x}$ is close to 0.5 , as it is suitable to any incompressible material having a transverse isotropy (Rahka and Laird, 1986). These observations agree with studies already performed at a more microscopic scale (Iricibar et al., 1977).

\subsection{The skin-pass: an example of loading history}

As mentioned in section 1, the propagation of Lüders bands can generate defects (vermiculation) during the forming. A skin-pass operation is often used before the stamping to eliminate this band apparition: a plastic strain, somewhat larger than the Lüders strain $\varepsilon_{\mathrm{LB}}$, is imposed on the metal sheet to trigger the Lüders bands during the pre-deformation process. The efficiency of the skin-pass operation is checked by testing samples of M323 steel skin-passed beforehand (2.5\%). The influence of a pre-strain on the propagation of the Lüders band is first investigated during interrupted tensile tests. The first unloading in figure $8 a$ shows that the bands stop their propagation as soon as the applied stress is suppressed. In the same way, the propagation restarts once the applied stress reaches the upper level. After the second unloading $\left(\varepsilon_{\mathrm{C}}>0.12\right)$, the Lüders bands have totally vanished and the sample deforms homogeneously again. This recovered homogeneity is what should be expected from a skin-pass process. However, figure $8 b$ shows that this operation only partly suppresses the band propagation: a slight strain-rate heterogeneity appears along the gauge part as soon as the skin-passed sample is plastically strained. For a skin-pass strain of $2.5 \%$, this systematic and significant heterogeneity can be attributed to the remnants of Lüders bands in as much as they vanish with drawing.

Industrially, skin-pass strains seldom exceed 3\%. To know if higher rates lead to a total disappearance of bands, samples having undergone skin pass strain up to $10 \%$ were requested from the steel manufacturer even if this figure is too large for general usage. The corresponding results are presented in figures $8 c$ and $8 d$ for respective strains of $7.5 \%$ and $10 \%$. 


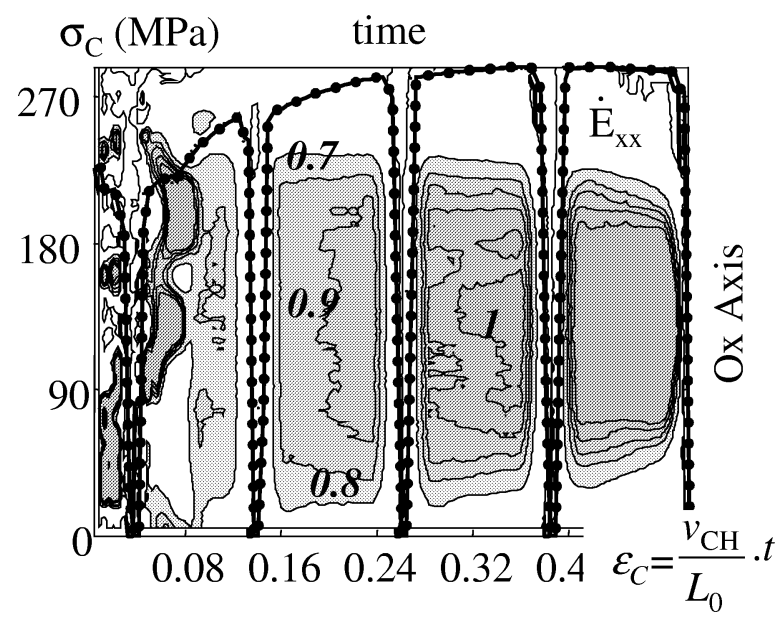

(a)

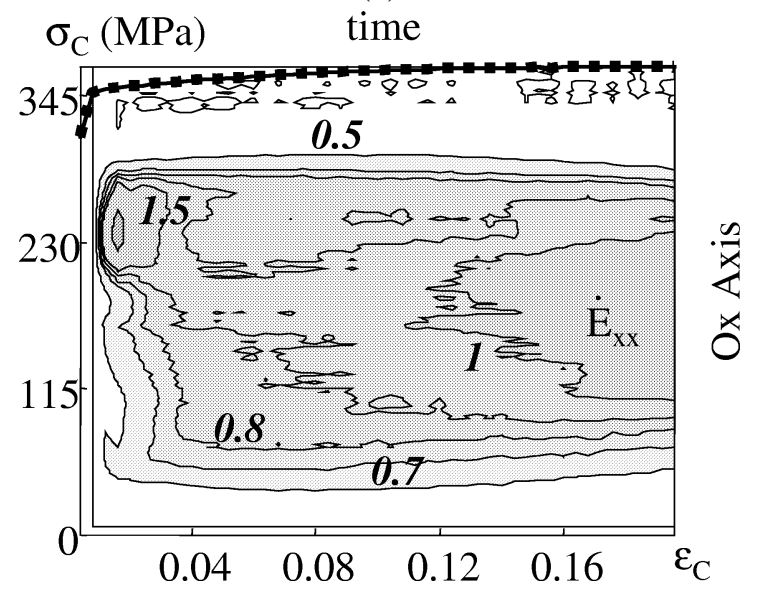

(c)

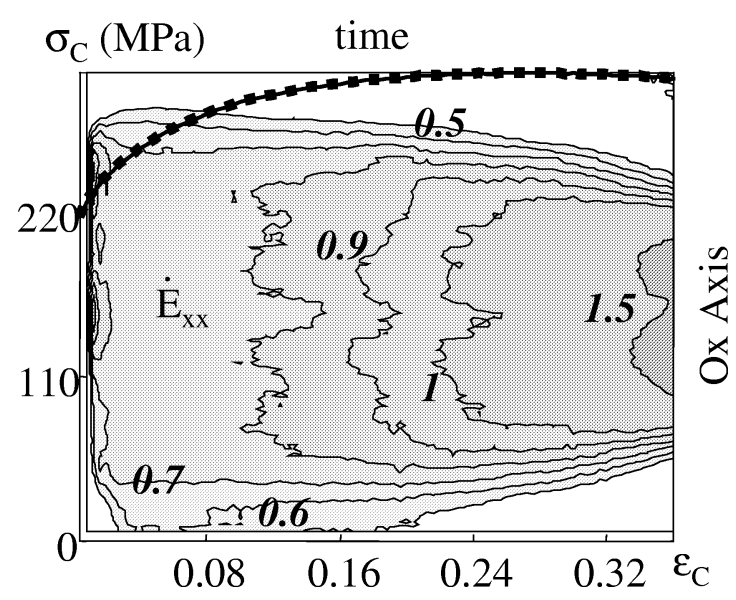

(b)

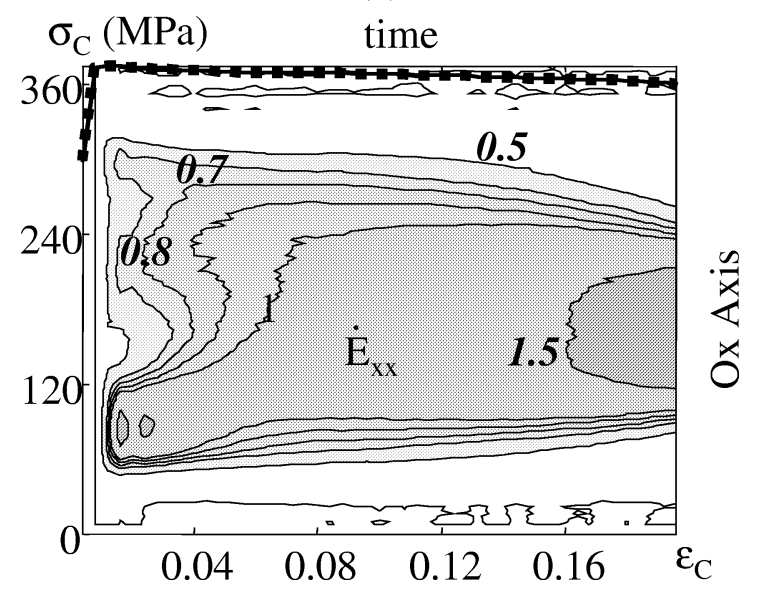

(d)

Figure 8. Influence of a pre-strain on the propagation of Lüders bands. Space-time-evolution of the axial Lagrangian strain rate $\dot{E}_{x x}(x, 0, t)$ in $10^{-3}$ $\mathrm{s}^{-1}$, for monotone tensile test, performed at constant velocity $\left(v_{\mathrm{CH}}=40 \mu \mathrm{m} . \mathrm{s}^{-1}\right)$, on M323 steel: (a) interrupted tensile test; (b) skin-pass strain: $2.5 \%$; (c) skin-pass strain: $7.5 \%$; (d) skin-pass strain: $10 \%$.

Whatever the strain, the strain-rate field remains heterogeneous from the yield stress. In figure $8 d$, the reader may also notice that the sample presents a softening as soon as it is plastically strained. The link between softening and localisation is resumed in the next section.

\section{Necking: a progressive but fatal phenomenon}

During mechanical loading, a ductile material passes more or less suddenly from a deformation mode for which strains are regularly distributed within the specimen (diffuse mode), to a mode for which strains concentrate (localised mode). This transition is commonly referred to as the necking process. This phenomenon is widely encountered during the forming of thin plates where it causes strong local thickness variations detrimental to aspect qualities and to mechanical properties of the final part. The considerable economic consequences related to necking phenomena have led to much research. For industrial applications, the 
experimental investigations of necking have often relied on the concept of the forming limit diagram where boundaries between homogeneous and localised flows are plotted in the principal strain plane for various loading paths (Veerman and Neve, 1972; Bragard et al., 1972; Hecker, 1975).

In the following paragraphs, we point out several characteristics of necking. We describe the properties of the associated strain field, the possible precocity of necking inception, the regularity and progressiveness of its development until fracture, and finally underline the strong influence of initial sample geometry.

\subsection{Strain state properties}

The evolution of strain distribution during loading is illustrated in figure 9, which illustrates a test performed on a 3CTi steel. This figure is divided into seven parts. First, the time evolution of the longitudinal Hencky strain profile is plotted in figure $9 a$. It shows that a zone of heterogeneous strains already exists when $\varepsilon_{\mathrm{C}}$ reaches $13 \%$. Then this zone progressively concentrates until the sample fracture. Four instants, labelled $a$ to $d$, corresponding to the conventional strains $\varepsilon_{\mathrm{C}}=12 \%, 20 \%, 28 \%$ and $32 \%$ respectively, are shown in this figure. The corresponding strain patterns are plotted in figures $9 b$ to $9 e$. They represent the distribution of the three in-plane components of the Hencky strain tensor. We observe that the components $\varepsilon_{x x}$ and $\varepsilon_{y y}$ are near constant along the sample width. The component $\varepsilon_{x y}$ remains small when compared with $\varepsilon_{x x}$ and $\varepsilon_{y y}$. Consequently, the principal axes (I, II) of $\varepsilon$ do not change very much and correspond to the frame of reference axes. The calculation of the contraction ratio $\bar{v}=-\varepsilon_{\mathrm{I}} / \varepsilon_{\mathrm{II}} \approx-\varepsilon_{y y} / \varepsilon_{x x}$ shows that the strain state throughout the test section of the sample correspond to a non-homogeneous tension state within an incompressible material with a transverse isotropy: $\bar{v}(x, y, t)=0.5$ (see figures $9 f-g$ ).

\subsection{Inception and development}

\subsubsection{From a diffuse to localised necking}

We have already underlined that a diffuse heterogeneity sometimes arises quite early during loading. Diffuse necking appears during the strain hardening in 3CTi (see figure $9 \mathrm{~g}$ ), just after the plastic plateau in SOLDUR 355 (see figure 10), and it is set just before the maximum load (Considère criterion) for the tests performed on HR55 and M323 steels (Chrysochoos et al., 1998).

For each tested grade of steel, once diffuse necking has appeared, the localised zone gradually narrows until sample fracture. The strain-rates within this concentration zone regularly increase. These results suggest that diffuse and localised necking are two consecutive aspects of the competition between strain hardening and damage mechanisms. In practice, it is then difficult to establish a definite boundary between these two 'localisation modes'.

The gradual development of necking is illustrated in figure 10 by defining three zones. Zone I corresponds to a quasi-homogeneous state where the strain-rate can be considered to be constant within the test section of the sample. Zone II.b is the part of the sample, which is actually deformed. The strain-rate progressively increases in this zone, while outside (II.a, II.c), it vanishes. We observe that the size of zone II.b decreases linearly with respect to $\varepsilon_{\mathrm{C}}$. In zone III, the strain-rate does not increase any longer. The size of this zone seems to remain constant. There, the strain-rate can reach 10 to 20 times the imposed 'macroscopic' strain-rate $\dot{\varepsilon}_{\mathrm{C}}$. Let us remark that these measurements are, at that moment, underestimated because data filtering tends to spread the localisation zone. Thus, the ultimate size of the necking zone strongly depends on the cut-off frequencies used by the image processing. 
(b) $\varepsilon_{\mathrm{C}}=12 \%$

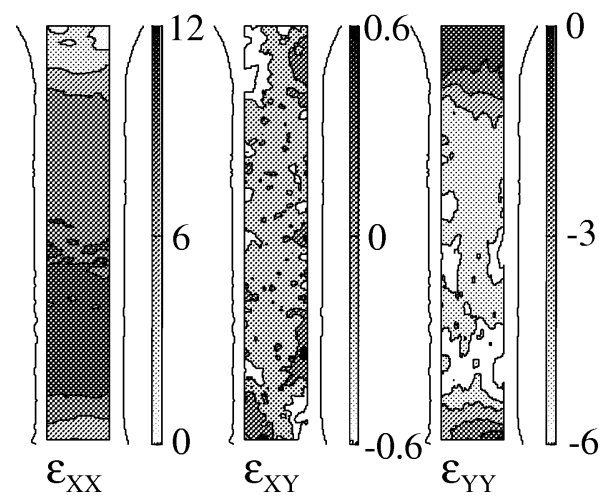

(f) $\varepsilon_{\mathrm{C}}=12 \%$ (c) $\varepsilon_{\mathrm{C}}=20 \%$

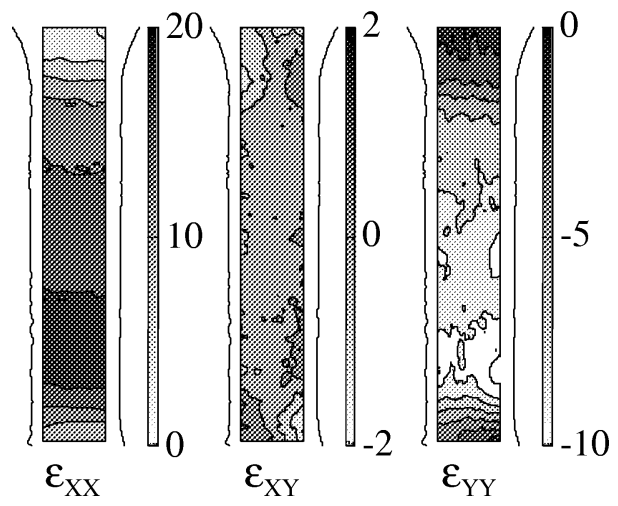

(g) $\varepsilon_{\mathrm{C}}=32 \%$

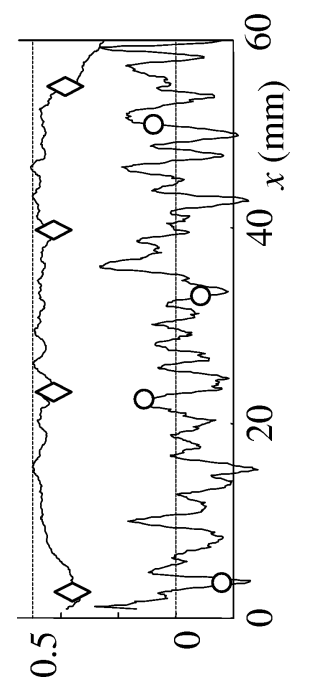

(d) $\varepsilon_{\mathrm{C}}=28 \%$

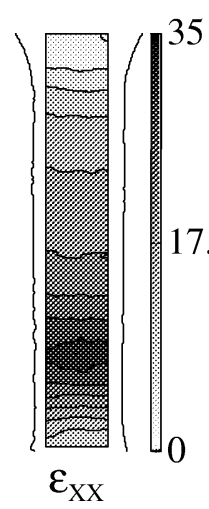

(a)

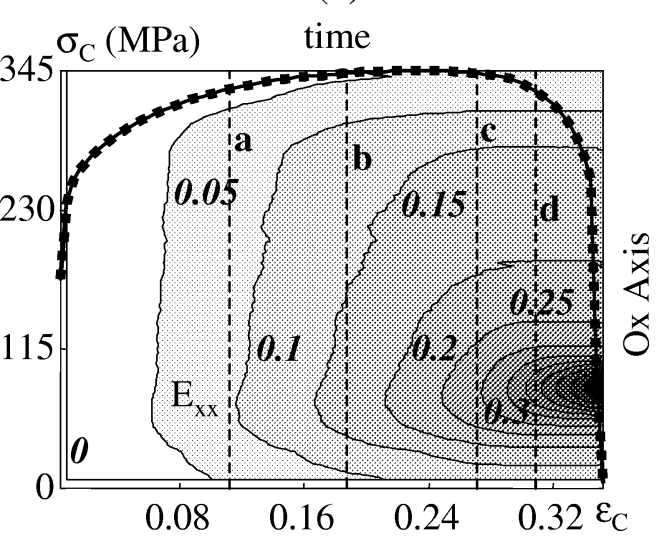

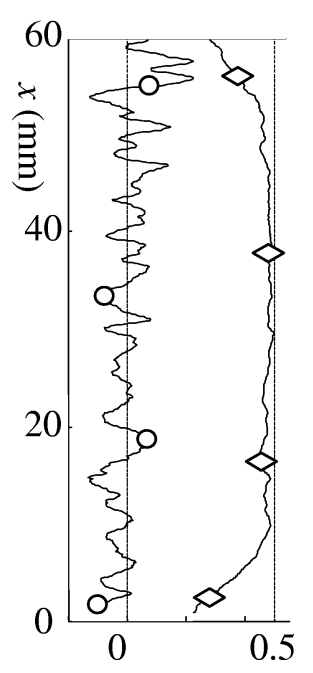

(e) $\varepsilon_{\mathrm{C}}=32 \%$
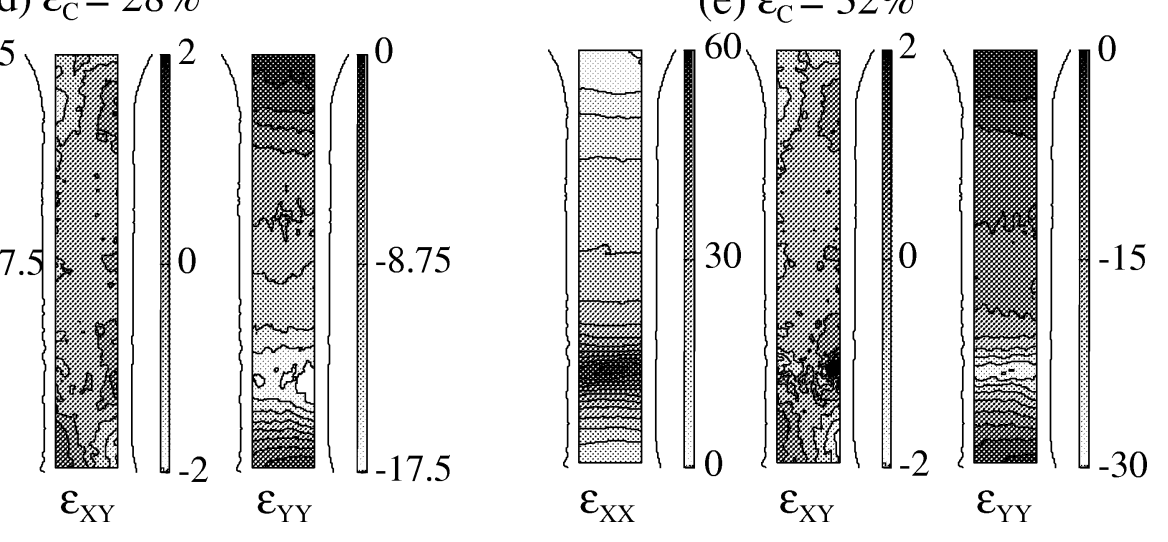

Figure 9. Strain state on a $3 \mathrm{CTi}$ specimen during a tension test: (a) corresponds to the time evolution of $\varepsilon_{x x}$ profile during this test; (b) to (e) represent the distribution of the components $\varepsilon_{x x}, \varepsilon_{x y}$ and $\varepsilon_{y y}$ of Hencky strain tensor for various loading states (in \%); (f) and (g) show the evolution of the ratios $\left\{-\varepsilon_{Y Y} / \varepsilon_{X X}(-\neg)\right.$ and $\left.\varepsilon_{X Y} / \varepsilon_{X X}(-\bigcirc-)\right\}$ along the sample axis for two loading states. 


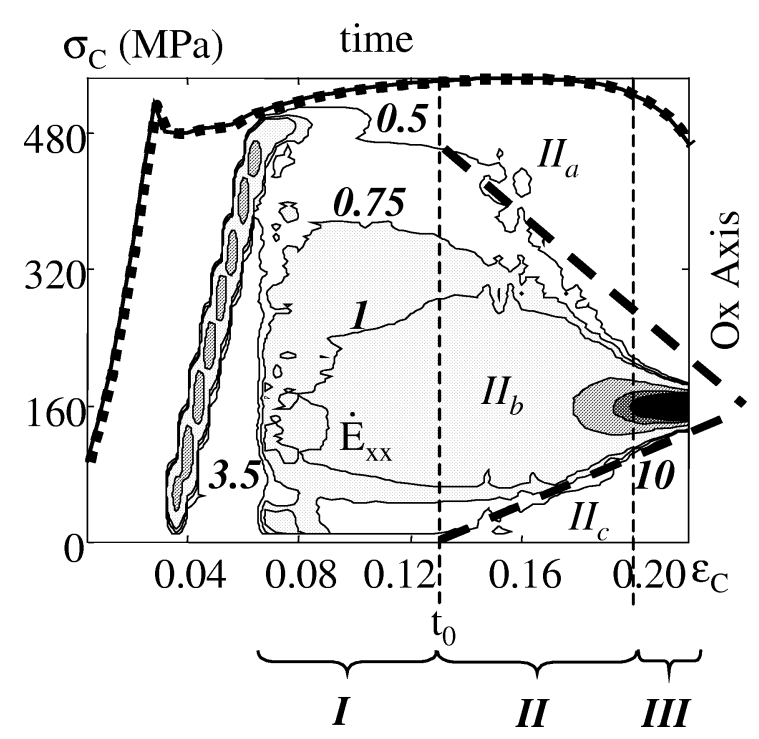

Figure 10. Time-evolution of $\dot{E}_{x x}(x, 0, t)$ profiles for monotone tensile test, performed at constant velocity $\left(v_{\mathrm{CH}}=50 \mu \mathrm{m} . \mathrm{s}^{-1}\right)$, on SOLDUR 355 steel sample (unit: $10^{-3} \mathrm{~s}^{-1}$ ).

Nevertheless, a longitudinal strain-rate can be estimated using a simple one-dimensional description. Although the experiment on SOLDUR 355 shows that the reduction of the localisation zone is not really symmetric and that the fracture does not exactly occur exactly in the middle of the sample (see figure 10), one supposes that the part of the sample $\widetilde{L}$, currently being deformed, narrows according to the relation:

$$
\widetilde{L}=L_{0}-2 v\left\langle t-t_{0}\right\rangle^{+}
$$

where $v$ is the mean 'reduction' velocity of the strained part and $t_{0}$ is the time corresponding to the onset of necking. The notation $\left\langle t-t_{0}\right\rangle^{+}$designates the positive part of $t-t_{0}\left(0\right.$ if $t-t_{0}<0$, and $t-t_{0}$ if $\left.t-t_{0} \geqslant 0\right)$. Before $t_{0}$, the strain-rate is considered to be homogeneous along the specimen axis.

For a velocity-controlled test, the corresponding velocity profiles along the sample axis are schematically plotted in figure 11.

According to this heuristic model, there is a geometrical point named $P_{\mathrm{F}}$ in the Lagrangian configuration displaying zero acceleration throughout the test. We will analyse the importance of this point that indicates the locus where the fracture will take place. By virtue of equation (11), the longitudinal strain-rate distribution during the tension test is written as:

$$
\dot{\varepsilon}_{x x}(t, x)= \begin{cases}0 & \text { if } x<v\left\langle t-t_{0}\right\rangle^{+} \\ v_{\mathrm{CH}} / \widetilde{L} & \text { if } v\left\langle t-t_{0}\right\rangle^{+} \leqslant x \leqslant L_{0}-v\left\langle t-t_{0}\right\rangle^{+}, \\ 0 & \text { if } x>L_{0}-v\left\langle t-t_{0}\right\rangle^{+}\end{cases}
$$

Parameters such as $L_{0}, v$, and $t_{0}$ are identified on each test to get a comparable evolution of the strain-rate within the localised zone at the beginning of necking. The time evolution of the strain-rate, obtained in the case of SOLDUR 355 steel, is drawn in figure 12.

At the beginning of the test, the slight difference observed between the measured and predicted strain-rate is simply due to the elastic loading of the testing machine (finite stiffness). The sudden increase of the strain-rate at time $t=40 \mathrm{~s}$ ( or $\varepsilon_{\mathrm{C}}=4 \%$ ) corresponds to the passage of the Lüders band. Of course, this effect is not taken 


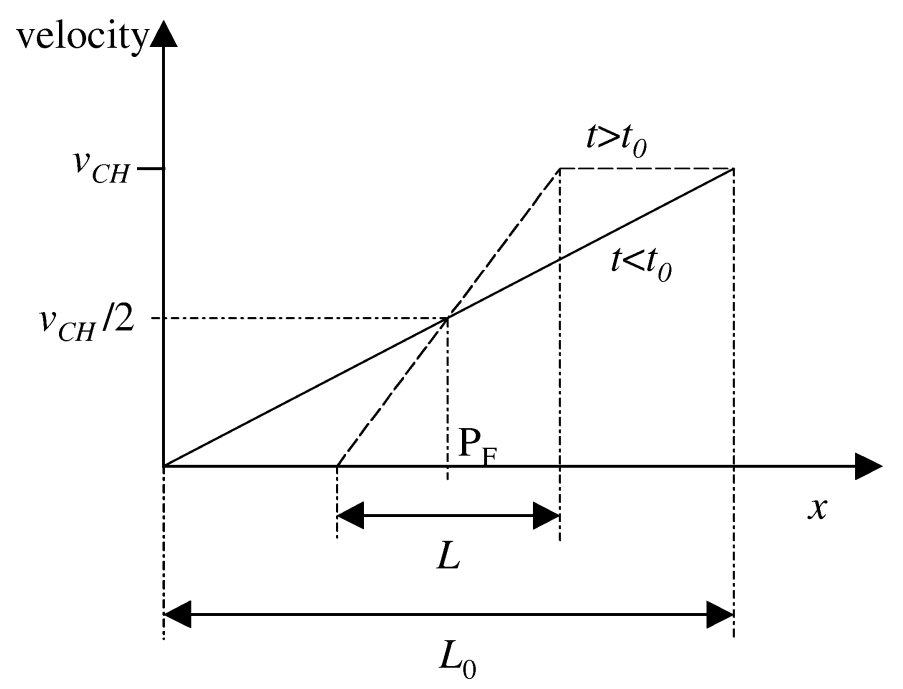

Figure 11. Velocity profiles along the sample longitudinal axis, before and after time $t_{0}$, that corresponds with inception of necking.

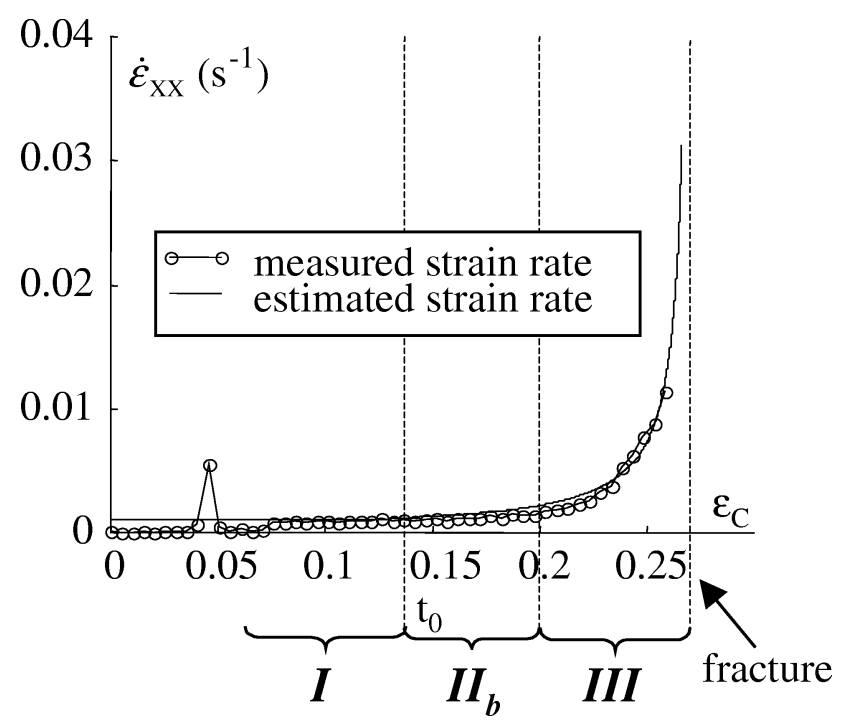

Figure 12. Model identification: comparison between measured and modelled strain rate at 'point' $P_{\mathrm{F}}$ on a test performed on a SOLDUR 355 steel sample.

into account by the simplistic model presented above. Otherwise, the good agreement between the model and the experimental response lead us to extend its predictions up to the fracture of the sample. To obtain an upper limit of the strain-rate, we assume that the fracture occurs when the size of the localised zone covers one grain diameter $(\phi=10 \mu \mathrm{m})$. Hence, the strain-rate reaches a value of around $5 \mathrm{~s}^{-1}$, i.e. more than a thousand times the macroscopic strain-rate $\dot{\varepsilon}_{\mathrm{C}}$.

\subsubsection{Last stage before rupture}

In the previous sub-sections, we have stressed the gradual development of necking. We would like now to discuss the last phase of its development, corresponding to the transition from localised necking to rupture. 
Localised necking is often characterised by the apparition of a narrow band, more or less tilted with regard to the loading axis, where strain (and strain-rate) increases considerably (Hill, 1952).

Figure 13 presents the surface distribution of the longitudinal Lagrangian strain-rate in the vicinity of the necking zone. In order to visualise the evolution of the sample geometry, the strain-rates are plotted in the actual configuration drawn using the displacement measurements. Results obtained on M323 and 3CTi steels are shown for four consecutive times spotted in the macroscopic stress-strain diagram (left). As for diffuse necking, the development of the localised band seems to be gradual too.

In the case of M323, two inclined zones regularly grow (see figures 13Aa, 13Ab) until one zone overcomes the other and finally leads to localised necking (see figures 13Ac, 13Ad). The angle between the loading axis and the localised zone is about $60^{\circ}$, which is not exactly the angle of $54.7^{\circ}$ predicted by Hill's theory for thin plates. This significant difference may be attributed to the relatively significant thickness of the plate $\left(e_{0}=0.7 \mathrm{~mm}\right)$ and to slight initial anisotropy stemming from the rolling process.

Concerning 3CTi steel, the strain-rate progressively concentrates in a zone that remains perpendicular to the loading axis. The final macroscopic crack, leading to rupture, begins in the middle of the localised zone, where the strain-rate is maximum (see figure 13B), as is often the case for massive samples $\left(e_{0}=2.9 \mathrm{~mm}\right.$ ).

However, even for relatively thin strips, the geometrical and/or material characteristics seem to induce triaxial effects within the localised necking zone, and could explain the different orientations of the localisation bands.
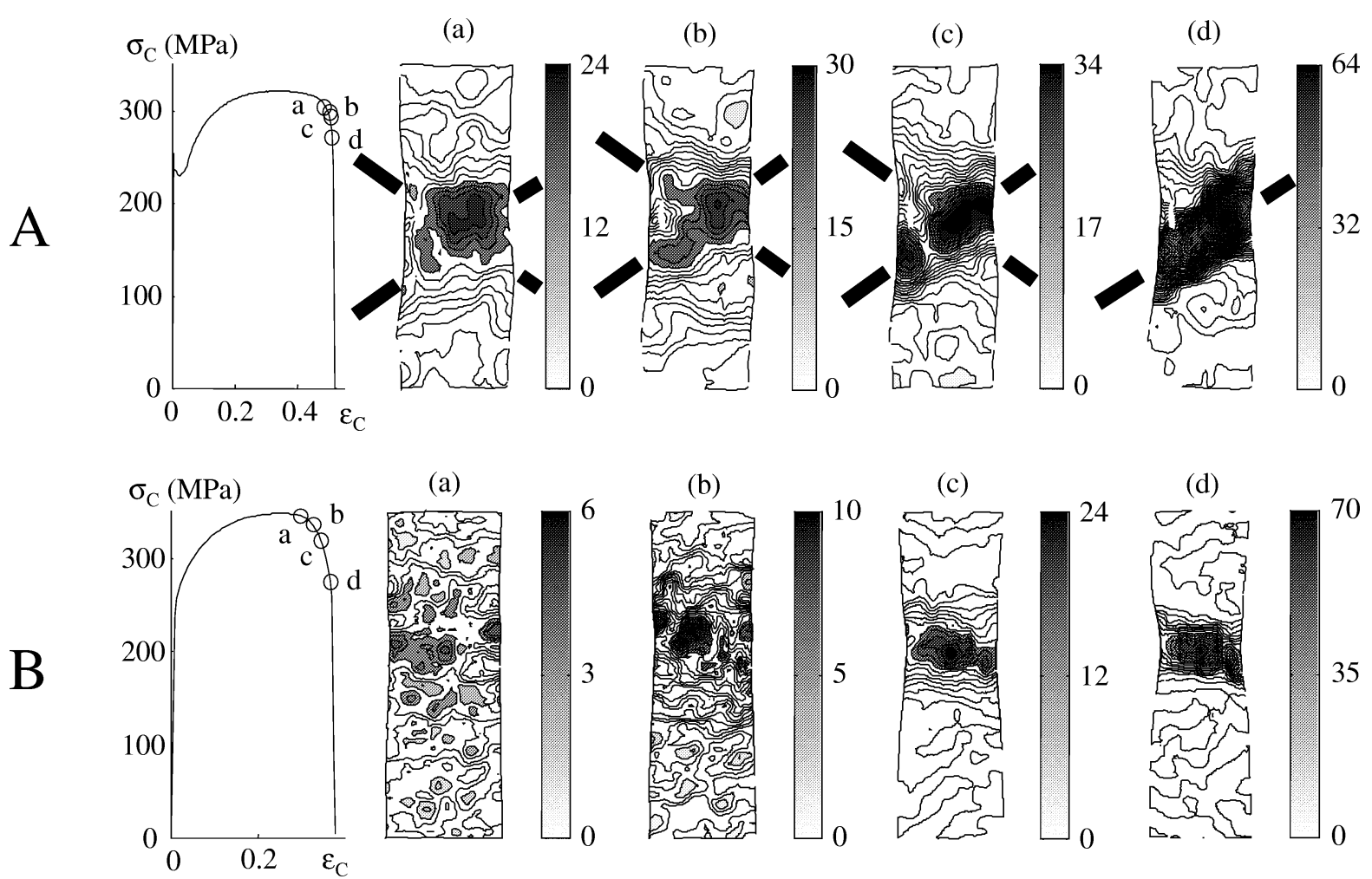

(a)

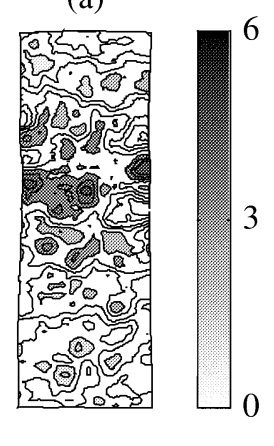

(b)

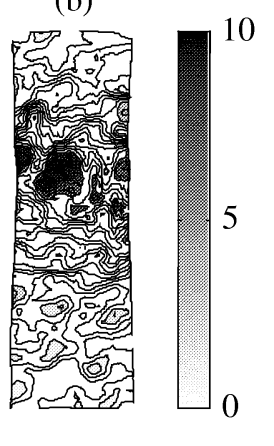

(c)

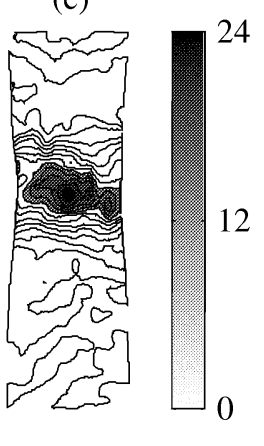

(d)

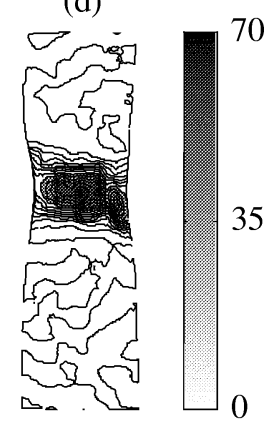

Figure 13. Axial Lagrangian strain rate spatial distribution $\dot{E}_{x x}(x, y)$ in the necking zone (unit: $10^{-3} \mathrm{~s}^{-1}$ ) at four loading states, for monotone tensile tests, performed at constant velocity $\left(v_{\mathrm{CH}}=40 \mu \mathrm{m} . \mathrm{s}^{-1}\right)$ : (A) M323 steel sample (initial dimensions of the observed zone: length $8.4 \mathrm{~mm}$, width $8.4 \mathrm{~mm}$, depth $0.7 \mathrm{~mm}$ ); (B) 3CTi steel sample (initial dimensions of the observed zone: length $8.5 \mathrm{~mm}$, width $8.5 \mathrm{~mm}$, depth $2.9 \mathrm{~mm}$ ). 


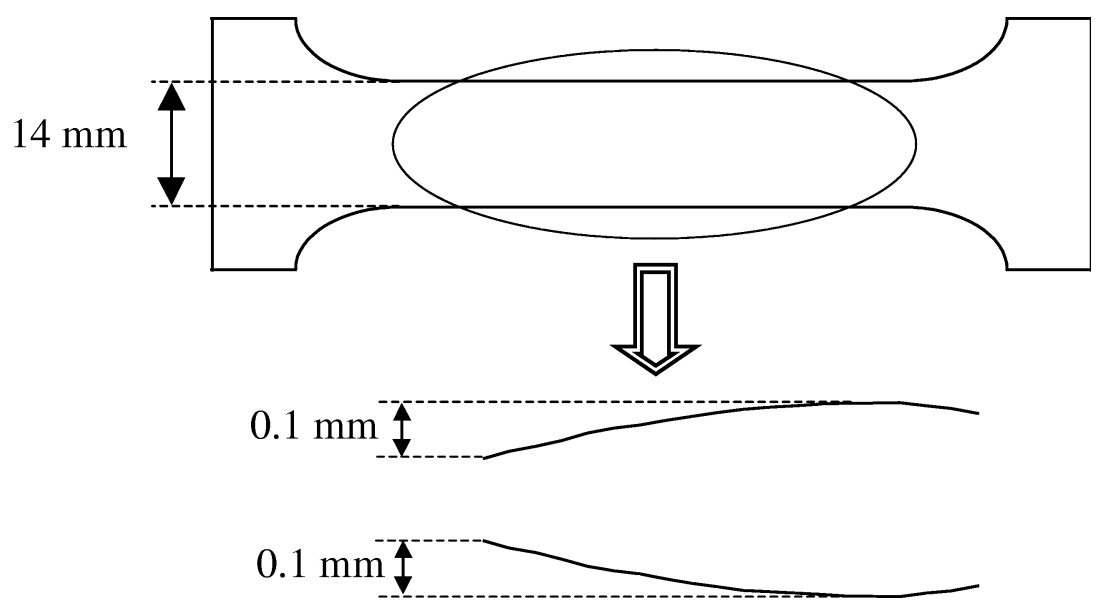

Figure 14. Heuristic sketch of the geometrical sample defects.

This result can have some importance from a numerical point of view. Indeed, the taking into account of this triaxiality effect requires costly three-dimensional calculations.

\subsection{Influence of geometry defects}

Pre-existing geometrical defects in a specimen affect the onset of localisation phenomena (Marciniak and Kuczynski, 1967). In what follows, the influence of geometry on the inception and development of necking is investigated by testing samples of the same material with or without measurable geometrical defects. These defects correspond to width variations along the sample axis. Their amplitude was estimated by using a threeaxis measurement machine (Renault Automation, accuracy $1 \mu \mathrm{m}$ ) with a maximum of around $0.2 \mathrm{~mm}$ (see figure 14).

Monotonic comparative tensile tests were performed at constant velocity on 3CTi steel, for both types of samples.

If they have similar loading curves $\left(\sigma_{C}-\varepsilon_{C}\right)$ (figure 15a), the associated strain-rate fields differ significantly (figures $15 b$ and $15 c$ ). Naturally, the sample presenting a geometrical defect shows an early developing heterogeneous strain state. For instance, the level curve $7.5 \cdot 10^{-4} \mathrm{~s}^{-1}$ appears at $\varepsilon_{\mathrm{C}}=12 \%$ for the "defectfree" sample and at $\varepsilon_{\mathrm{C}}=4 \%$ for the other one.

\section{Toward a local identification of the constitutive equations}

An important asset for the identification of the mechanical constitutive equations is to obtain a correspondence between stress and strain. As previously underlined, the strain state of the sample becomes heterogeneous in the course of loading so that the usual identification process, based on homogeneous mechanical fields, becomes hazardous. Indeed, if the estimate of a local strain during the loading can easily be determined by the correlation technique, a direct evaluation of the stress is more difficult, if not impossible. Two basic ways are generally followed to 'measure' a stress:

- from a strain measurement via the knowledge of the material behaviour (understand elastic behaviour!);

- from a force measurement assuming that the distribution of stresses on the gauge section of the sample is known. 


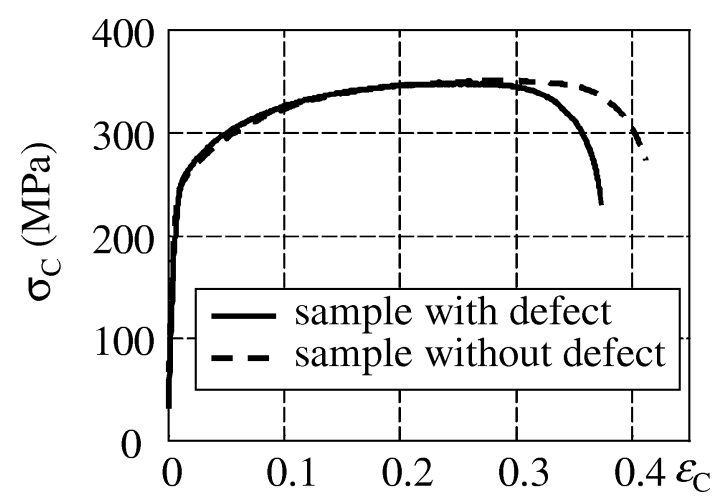

(a)

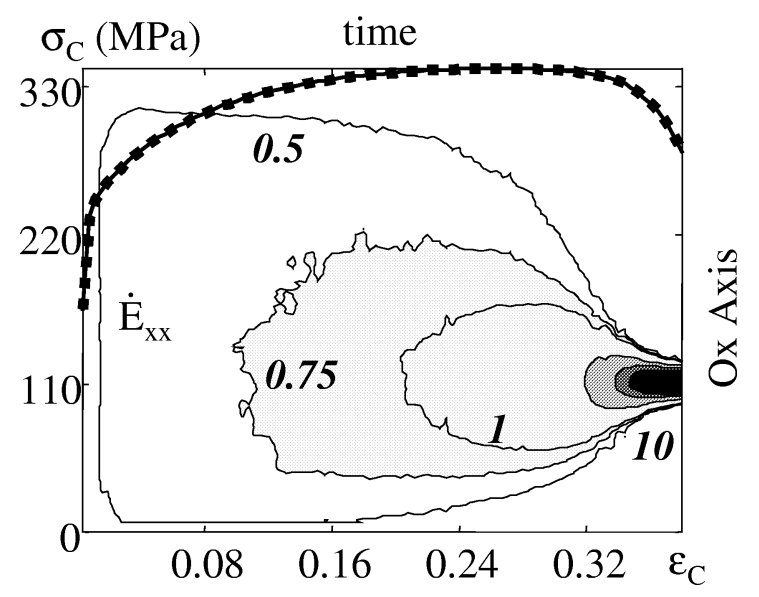

(b)

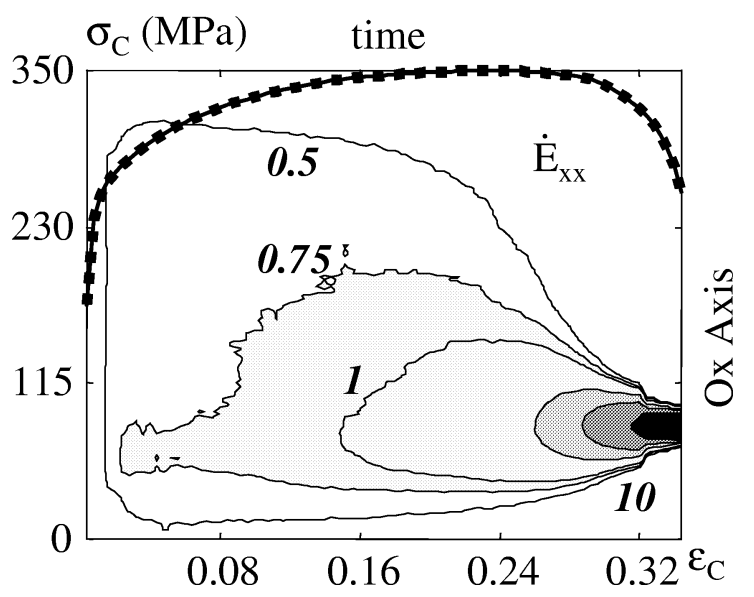

(c)

Figure 15. Influence of slight geometrical defect on a 3CTi steel sample: (a) comparison of conventional stress-strain curves; (b) no measurable defect within the test section of the specimen; (c) presence of a defect.

In what follows, we will propose a way to construct a stress field. The method is partly founded on the numerical integration of equilibrium equations. Nevertheless, to make this operation possible, a certain number of hypotheses have to be made concerning the stress tensor components.

\subsection{A quasi-static development of localisation}

In section 4, we have seen that during necking, the strain-rate regularly increases in a certain zone until fracture occurs. Consequently, acceleration quantities develop during the test and it becomes legitimate to attribute possible local dynamic phenomena to a quasi static loading process. Strain measurements allow a first glimpse of the amplitude of dynamic effects. The numerical results plotted in figure 16a are derived from equation (12). The level curve characterising a zero acceleration $(\gamma=0)$ is associated with the point $P_{\mathrm{F}}$. The experimental results for a test performed on a SOLDUR 355 steel sample are shown in figure $16 b$ that gives the time evolution of the $\gamma_{x}(x, y=0, t)$, after the Lüders band has propagated. As seen previously, by assuming that fracture occurs when the localised zone has reached one grain size and by extending the validity of equation (12), the upper bound of acceleration is then about $0.8 \mathrm{~mm} . \mathrm{s}^{-2}$. 


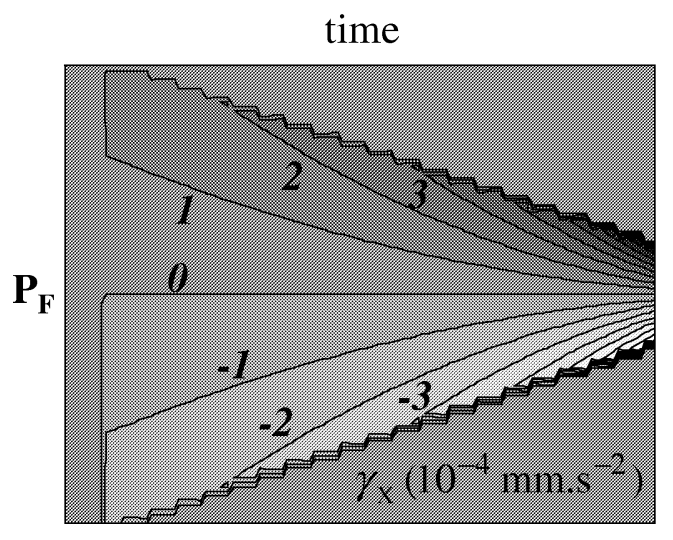

(a)

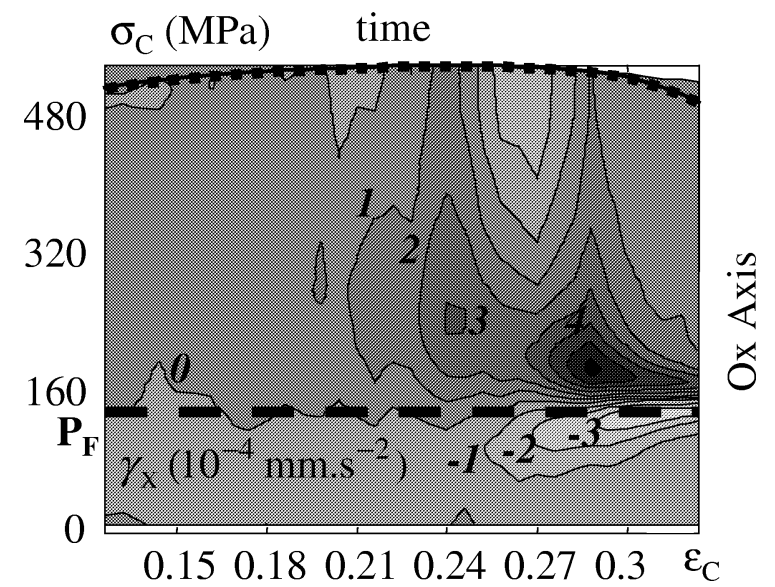

(b)

Figure 16. Comparison between measured and calculated profiles of acceleration in the tensile direction for a test performed on SOLDUR 355 steel sample: (a) calculation; (b) measurement.

This order of magnitude remains very small compared to acceleration due to gravity, the latter being itself traditionally neglected in tensile tests on metal strips. These approximations and the use of local equilibrium equations imply that the divergence of the stress tensor must remain equal to zero. In the next section such a result is used to construct a local stress-strain diagram.

\subsection{A stress state construction}

When acceleration due to gravity is neglected, the equilibrium equations become:

$$
\underline{\operatorname{div}}(\underline{\underline{\sigma}})=\underline{0} \text {. }
$$

Although we have already noticed that the thin plate assumption may be unsound for metal sheets of standard thickness, we use it in the following work. This strongly simplifies the equilibrium equations, which become with respect to the frame of reference of the sample:

$$
\left\{\begin{array}{l}
\frac{\partial \sigma_{x x}(x, y, t)}{\partial x}+\frac{\partial \sigma_{x y}(x, y, t)}{\partial y}=0 \\
\frac{\partial \sigma_{x y}(x, y, t)}{\partial x}+\frac{\partial \sigma_{y y}(x, y, t)}{\partial y}=0
\end{array}\right.
$$

As recalled above, we must now admit a stress distribution for the components $\sigma_{x x}$ in each cross-section of the sample. During tensile tests, this component is classically considered to be uniform on each cross-section. So we get:

$$
\sigma_{x x}(x, t)=\frac{F(t)}{S_{0}} \exp \left(\varepsilon_{x x}(x, t)\right) .
$$

Then, the use of equation (14-a) leads to:

$$
\sigma_{x y}(x, y, t)=-\sigma_{x x}(x, t) \frac{\partial \varepsilon_{x x}(x, t)}{\partial x} y+B(x, t),
$$


where $B(x, t)$ is an integration constant relative to the space variable $y$. Except in the very last part of the necking, we observed that the strain measurements of $\varepsilon_{y y}$ are symmetrically distributed along the width of the sample. This property yields a symmetric reduction of sample sections. The axis of symmetry, being the neutral axis of the sample, remains a straight line during necking. The constant $B(x, t)$ then vanishes as soon as the shear force for each cross-section is considered to be zero. This hypothesis leads to an odd distribution of the shear stresses with regard to the $O x$ direction:

$$
\sigma_{x y}(x, y, t)=-\sigma_{x x}(x, t) \frac{\partial \varepsilon_{x x}(x, t)}{\partial x} y .
$$

Naturally, in the presence of inclined localisation bands, shear forces may appear and $B(x, t)$ must be determined.

The integration of the last equilibrium equation (14-b), gives a parabolic distribution of components $\sigma_{y y}$ that can be written as:

$$
\sigma_{y y}(x, y, t)=-\frac{\partial}{\partial x}\left(\sigma_{x x}(x, t) \frac{\partial \varepsilon_{x x}(x, t)}{\partial x}\right) \cdot \frac{y^{2}}{2}+C(x, t) .
$$

The sample being non loaded on its lateral surfaces $(y= \pm l(x, t) / 2)$, the normal component $\sigma_{y y}$ equals zero:

$$
\underline{\underline{y}} \underline{\underline{\underline{\sigma}}}(x, \pm l / 2, t) \cdot \underline{y}=\sigma_{y y}(x, \pm l / 2, t)=0 .
$$

Hence, by using equations (18), (19), we get:

$$
\sigma_{y y}(x, y, t)=\frac{\partial}{\partial x}\left(\frac{\sigma_{x x}(x, t)}{2} \frac{\partial \varepsilon_{x x}(x, t)}{\partial x}\right) \cdot\left(\frac{l(x, t)^{2}}{4}-y^{2}\right) .
$$

Equations (15), (17), (20) can be used to estimate numerically the stress field for grids corresponding to the experimental measures of strain. Results are shown in figure 17; level curves for the stress components $\sigma_{x x}$, $\sigma_{x y}, \sigma_{y y}$ have been plotted for the two conventional strains corresponding to figures $9 b$ and $9 e$.

(a) $\varepsilon_{\mathrm{C}}=0.12$

(b) $\varepsilon_{\mathrm{C}}=0.32$

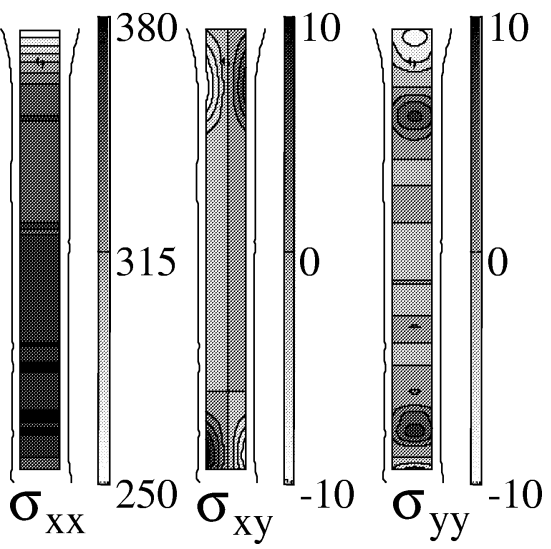

(a)
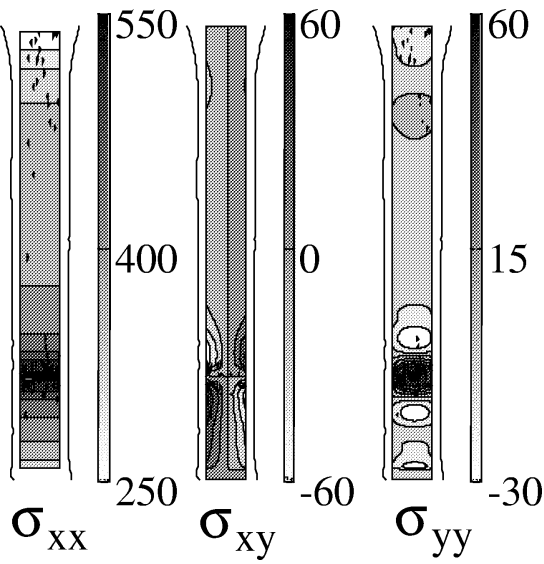

(b)

Figure 17. Stress computations. The stress distributions (a) and (b) correspond to stages (a) and (d) of figure 9. Stress unit: (MPa). 
The shear stresses $\sigma_{x y}$ are approximately of the same order of magnitude as $\sigma_{y y}$, and both remain small compared to $\sigma_{x x}$. For $\varepsilon_{\mathrm{C}}=0.12$, as expected, a shear stress concentration can be observed in the connection zones. These concentrations due to the specimen geometry are not related to any strain localisation. For $\varepsilon_{\mathrm{C}}=0.32$, stress concentrations still exist in the connection zones, but are of an order of magnitude which is weaker than the one associated with necking. In the necking zone, the stress concentration accompanies the strain localisation.

\subsection{Stress-strain diagrams}

It is now of interest to compare different representations of the stress-strain diagram of the tensile test. In figures $18 a$ and $18 b$ a set of three curves $\left(\sigma_{x x}, \varepsilon_{x x}\right)$ has been plotted for three points (sections) of the $O x$ axis for two conventional strain levels. The initial gauge length of the (virtual) optical extensometer used in that case is about $L_{0} / 50$. As usual, the conventional curve $\left(\sigma_{\mathrm{C}}, \varepsilon_{\mathrm{C}}\right)$ is also plotted.

At the beginning of the hardening, all the curves seem to describe a unique path (figure 18a). In fact, the final loading states reached at $\varepsilon_{\mathrm{C}}=15 \%$, are not the same and this because of strain localisation. Once the structure has started to soften (figure 18b), $\sigma_{x x}$ decreases in sections for which the strain-rate vanishes (extensometers $A$ and $B$ ), while $\sigma_{x x}$ continues to increase in sections belonging to the current necking zone (extensometer $C$ ). The final spread of the local stress-strain curves $\left(\sigma_{x x}, \varepsilon_{x x}\right)$ is given for the macroscopic loading represented in figure $13 B\left(\varepsilon_{\mathrm{C}}=36 \%\right)$. Note that until this ultimate loading, the stress component $\sigma_{x x}$ in the localisation zone constantly increases. It thus seems that plastic softening, translated by a non-monotone loading, is induced by a local hardening followed by an elastic unloading in cross-sections external to the localisation zone.

Hence, the strain softening seems to be more a structure effect rather than an intrinsic property of the material. The intrinsic character of softening mechanisms in the case of rate-independent materials has often been discussed in the literature (Mazars and Bazant, 1989). This open question is of importance in as much as

(a) $\varepsilon_{\mathrm{C}} \leq 15 \%$

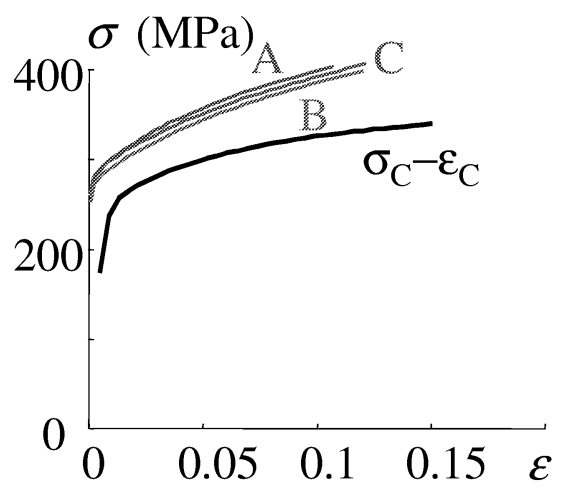

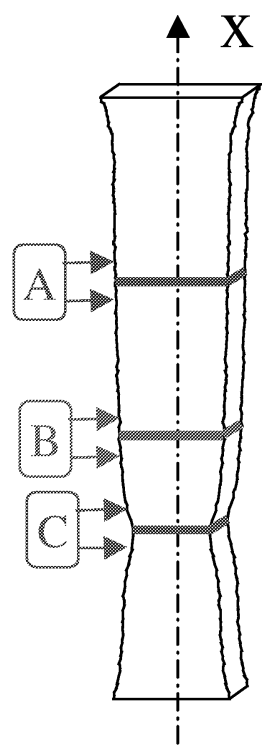

(b) $\varepsilon_{\mathrm{C}} \leq 36 \%$

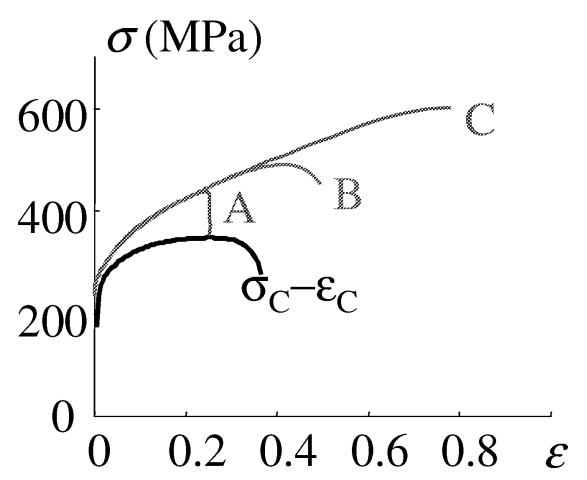

Figure 18. Stress-strain diagrams (3CTi): (a) $\varepsilon_{\mathrm{C}} \leqslant 15 \%$, zoom of the beginning of the hardening curves $\mathrm{A}$ and $\mathrm{B}$, initially superimposed with curve $\mathrm{C}$ were vertically shifted; (b) $\varepsilon_{\mathrm{C}} \leqslant 36 \%$, whole stress-strain curve up to fracture. 
the use of behaviour models being able to predict softening is essential to make a whole class of localisation criteria operational (Hill, 1958; Barbier et al., 1998).

\section{Concluding comments}

Image processing, based on digital image correlation, was used to study different localisation mechanisms on steel samples. The experimental set-up provided some substantial information concerning the inception and the propagation of the Lüders bands (transversal and longitudinal propagation velocities), the strain state within the bands and their geometrical characteristics (angle with the loading axis). For the materials studied and at our observation scale, the strain state within the bands corresponds to a simple tension state for incompressible materials: we experimentally verified that $\varepsilon_{y y} \approx-\varepsilon_{x x} / 2, \varepsilon_{x y} \approx 0$. In all cases, by measuring thickness variations, the incompressibility and transverse isotropy properties leading to $\varepsilon_{y y} \approx \varepsilon_{z z}$ were shown. The experimental data also showed that the skin-pass operation partly suppresses the Lüders bands for traditional skin-pass strains. For higher pre-strains, this operation has generated heterogeneity in the strain fields, interpreted as germs of localisation.

Concerning the necking phenomenon, results suggested an early and progressive emergence of diffuse and localised necking during a quasi-static, velocity-controlled, tensile test. We verified that the geometrical defects acted as catalysts for localisation inception. At the scale of our experimental observations, acceleration quantities were shown to be negligible compared to the power of the internal forces developed during necking. This indicates the quasi-staticity of such deformation processes. An immediate implication of the precocious apparition of non uniformity of the strain fields, which is of great practical importance, is that the section test of a standard specimen must be considered as a structure and not as an elementary volume evenly stressed and strained.

To locally estimate a stress tensor, a method founded on the integration of the equilibrium equations - using the plane stress hypothesis - and using strain measurements, was proposed. Obtaining a stress field made it possible to build different local tension curves. Their analysis led us to wonder about the intrinsic character of the softening concept sometimes put forward to explain the strain localisation.

The localisation mechanisms were also analysed by using infrared thermography. The goal of the infrared data processing was to deduce the distribution of heat sources from thermal images. The very high correlation between kinematic and calorimetric data has been underlined in (Wattrisse, 1999; Louche, 1999; Chrysochoos et al., 1998). From a theoretical viewpoint, it is quite easy to imagine that the places where the strains concentrate, are those where irreversibility develops. The simultaneous obtaining of stress, strain-rate and dissipation fields should also lead to an indirect estimate of the stored energy rate pattern during strain hardening. These supplementary experimental data are useful to check the validity of the thermomechanical description of the behaviour. Indeed, the rate of stored energy represents the power associated with the internal state variables, which are chosen to sum up the microstructural evolutions at a more macroscopic scale. From a thermodynamic viewpoint, the stored energy variations are directly related to the free energy potential variations. Thus, this kind of information should be very useful to a posteriori justify the choices of state variables introduced to describe work hardening and damage. They should also suggest possible forms of complementary laws compatible with irreversibilities experimentally evidenced, and thus would ensure the mechanical and thermodynamic consistence of the behavioural models, the constitutive equations of which are omnipresent in the current works on localisation. 


\section{References}

Aifantis E.C., 1992. On the role of gradients in the localization of deformation and fracture. Int. J. Engng. Sci. 30, 1279-1299.

Bai Y.L., 1982. Thermo-plastic instability in simple shear. J. Mech. Phys. Solids 30, 195-207.

Bailey H.H., Blackwell F.W., Lowery C.L., Ratkovic J.A., 1976. Image correlation: Part I. Simulation and analysis, Report prepared for United States Air Force Project RAND, R-2057/1-PR.

Barbier G., Benallal A., Cano V., 1998. Relation théorique entre la méthode de perturbation linéaire et l'analyse de bifurcation pour la prédiction de la localisation des déformations. C. R. Acad. Sci. Paris Série IIb 326, 153-158.

Béranger G., Henry G., Sanz G., 1994. Le livre de l'acier, Lavoisier Tec\&Doc, Paris.

Bragard A., Baret J.C., Bonnarens H., 1972. A simplified method to determine the F.L.D. onset of localised necking, Rapport Centre de Recherche de la Métallurgie 35, 33.

Bruck H.A., Mc Neill S.R., Sutton M.A., Peters W.H., 1989. Digital image correlation using Newton-Raphson method of partial differential correction. Exp. Mech., 261-267.

Choi S., Shah S.P., 1997. Measurement of deformations on concrete subjected to compression using image correlation. Exp. Mech. 37, $307-313$.

Chrysochoos A., Louche H., Muracciole J.M., Saurel J.L., Némoz-Gaillard M., Wattrisse B., 1998. Experimental analysis of localization mechanisms in steels by infrared and speckle image processing. In: Lagarde (Ed.), Proc. IUTAM Symp. on Photomechanics, Kluwer, Dordrecht, pp. 313-320.

Considère A., 1885. Mémoire sur l'emploi du fer et de l'acier dans les constructions. Annales des Ponts et Chaussées 9, 574.

Estrin Y., Kubin L.P., 1988. Plastic instabilities: classification and physical mechanisms. Res. Mechanica 23, 197-221.

Estrin Y., Kubin L.P., 1991. Plastic instabilities: phenomenology and theory. Materials Science and Engineering 137, $125-134$.

Fressengeas C., Molinari A., 1985. Inertia and thermal effects on the localization of plastic flow. Acta Metall. 33, 387-396.

Germain P., 1986. Mécanique - Tome I, Ellipses, Paris.

Hähner P., 1994. Theory of solitary plastic waves - Part I. Appl. Phys. 58, 41-48.

Hecker S.S., 1975. A simple forming limit curve technique and results, on aluminium alloys. Sheet Metal Industries 52, 671-676.

Hill R., 1952. On discontinuous plastic states with spatial special reference to localised necking in thin sheets. J. Mech. Phys. Solids 1, 19-30.

Hill R., 1958. A general theory of uniqueness and stability in elastic-plastic solids. J. Mech. Phys. Solids 6, 236-249.

Iricibar R., Mazza J., Cabo A., 1977. On the Lüders front in mild steel - I, Acta Met. 25, 1163-1168.

Louche H., 1999. Analyse par thermographie infrarouge des effets dissipatifs de la localisation dans des aciers, PhD thesis, University of Montpellier, France.

Marciniak Z., Kuczynski K., 1967. Limit strains in the process of stretch forming sheet metal. Int. J. Mechanical Sciences 9, 609-620.

Mazars J., Bazant Z.P., 1989. Cracking and Damage: Strain Localisation and Size Effect, Elsevier Science Publishers LTD, Barking.

Oulamara A., Tribillon G., Duvernoy J., 1988. Subpixel speckle displacement measurement using a digital processing technique. J. Mod. Opt. 35.

Pijodier-Cabot G., Benallal A., 1993. Strain localisation and bifurcation in a non-local continuum. Int. J. Solids Structures 30, 1761-1775.

Rahka K., Laird C., 1986. Poisson's ration as determined for elastic and plastic deformation and for monotonic and cyclic loading - Part I: critical review. J. Testing and Evaluation 14, 173-180.

Rice J.R., 1976. The localization of plastic deformation. In: Koiter W.T. (Ed.), Th. Appl. Mech., North-Holland Publishing Company, pp. 207-220. Rougée P., 1997. Mécanique des grandes transformations, S.M.A.I. Mathématiques \& Applications, Vol. 25, Springer, Berlin.

Strudel J.L., 1979. Interactions des dislocations avec des impuretés mobiles. In: Groh P., Kubin J.-L., Martin J.-L. (Eds.), Ecole d'été d'Yravals: Dislocations et Déformation Plastique, pp. 199-222.

Veerman C., Neve P.F., 1972. Some aspects of the determination of the forming limit diagram - Onset of localized necking. Sheet Metal Industries 49, 421-423.

Wattrisse B., 1999. Etude cinématique des phénomènes de localisation dans des aciers par intercorrélation d'images, PhD thesis, University of Montpellier, France.

Wattrisse B., Chrysochoos A., Muracciole J.M., Némoz-Gaillard M., 2000. Analysis of strain localisation during tensile tests by digital image correlation. Exp. Mech., in press.

Zaiser M., Hähner P., 1997. Oscillatory modes of plastic deformation: theoretical concepts. Phys. Stat. Sol. (b) 199, 267-330. 